\title{
Ocorrência de intercalação de rocha fosfática na Formação Ponta Grossa em Rio Verde de Mato Grosso, Mato Grosso do Sul: implicações paleoambientais Phosphatic strata from Ponta Grossa Formation in Rio Verde de Mato Grosso, Mato Grosso do Sul, Brazil: palaeoenvironmental implications
}

\author{
Cibele Carolina Montibeller ${ }^{1}$, Antenor Zanardo², Guillermo Rafael Beltran Navarro ${ }^{2}$ \\ ${ }^{1}$ Pós-Graduação em Geociências e Meio Ambiente, Instituto de Geociências e Ciências Exatas, Universidade Estadual Paulista \\ "Júlio de Mesquita Filho" - UNESP, Avenida 24-A, 1.515, Bela Vista, \\ CEP 13506-900, Rio Claro, SP, BR (cibele.cm@outlook.com) \\ ²Departamento de Petrologia e Metalogenia, Instituto de Geociências e Ciências Exatas, \\ UNESP, Rio Claro, SP, BR (azanardo@rc.unesp.br; navarro@rc.unesp.br)
}

Recebido em 17 de março de 2016; aceito em 01 de fevereiro de 2018

\begin{abstract}
Resumo
Entre as rochas da Formação Ponta Grossa, aflorantes no município de Rio Verde de Mato Grosso, é registrada a presença de camadas constituídas predominantemente por apatita, não fossilíferas, que ocorrem como estratos destacados intercalados em folhelhos cinzas-escuros a pretos. Petrograficamente, essa rocha fosfática apresenta estrutura sutilmente laminada e não são observadas feições indicativas de algas, restos fósseis ou de estruturas orgânicas. Possui teores de $\mathrm{P}_{2} \mathrm{O}_{5}$ variando entre 12,96 e $23,35 \%$, teores de $\mathrm{CaO}$ variando entre 19,85 e 33,04\%, e possui alta concentração de elementos terras raras (ETR) em relação à média da crosta continental superior. Essa ocorrência não possui evidências de ação biogênica — o que é confirmado pela microscopia eletrônica - e possui relictos de oxi-hidróxidos, preferencialmente de ferro, com pequena quantidade de manganês, sugerindo origem pela dessorção de fosfato por comportamento redox a partir desses relictos. As condições de formação dessas fosforitas - se não condicionadas a aporte externo de oxi-hidróxidos de ferro pela proximidade da costa, por ambientes deltaicos ou por contribuições hidrotermais e/ou vulcânicas - colocam as camadas fosfáticas de Rio Verde de Mato Grosso, Mato Grosso do Sul, em condições de ambiente marinho plataformal raso, com profundidade entre 200 e $300 \mathrm{~m}$, de águas frias e com baixa salinidade, preferencialmente anóxico, e suscetível a estabelecimento de zona de ressurgência.
\end{abstract}

Palavras-chave: Fosforita; Fosfogênese; Devoniano; Bacia do Paraná; Formação Ponta Grossa.

\begin{abstract}
Amongst rocks of the Ponta Grossa Formation cropping out in Rio Verde de Mato Grosso, there are levels consisting predominantly of apatite, without fossil traces, which occur as layers hosted in gray to black shales. Petrographically, this phosphatic level has subtly layered structure and no features indicative of algae, fossil remains or organic structures. It has $\mathrm{P}_{2} \mathrm{O}_{5}$ content varying between 12.96 and $23.35 \%, \mathrm{CaO}$ ranging between 19.85 and $33.04 \%$, and high concentration of rare earth elements (REE) when compared to the average content of the upper continental crust. This occurrence exhibits no evidence of biogenic action, which is confirmed by electron microscopy, yet it contains relicts of oxy-hydroxides, predominantly of iron, with small amount of manganese, suggesting origin from phosphate desorption due to the redox behavior of these oxy-hydroxides. If these phosphorites were not subject to external supply of iron oxy-hydroxides due to proximity to the coast, deltaic environments or hydrothermal and/or volcanic contributions, then the phosphatic levels of Rio Verde de Mato Grosso, Mato Grosso do Sul, probably formed on a shallow marine platform at depths between 200 and $300 \mathrm{~m}$, in cold, low salinity and preferably anoxic water, subject to upwelling.
\end{abstract}

Keywords: Phosphorite; Phosphogenesis; Devonian; Paraná Basin; Ponta Grossa Formation. 


\section{INTRODUÇÃO}

A Formação Ponta Grossa é uma unidade sedimentar devoniana pertencente ao Grupo Paraná, que aflora nos estados do Paraná, Goiás, Mato Grosso e Mato Grosso do Sul, e cuja seção tipo, descrita por Oliveira (1912), localiza-se próxima à cidade de Ponta Grossa, Paraná. No estado de Mato Grosso do Sul, o Grupo Paraná aflora em uma faixa aproximadamente contínua e de largura entre 20 e 30 km, com direção NNE-SSW (Figura 1), que se estende desde cerca de $10 \mathrm{~km}$ a nordeste da cidade de Aquidauana até o município de Sonora, extremo norte do estado (Lacerda Filho et al., 2006).

O Grupo Paraná, correspondente à Supersequência Paraná (Milani, 1997), é subdividido em Formação Furnas pacote arenoso na base da sequência - e Formação Ponta Grossa - pacote pelítico superior. Segundo Assine et al. (1994), a sequência devoniana da Bacia do Paraná inicia-se com um pacote psamítico/psefítico continental, sendo gradualmente sobreposto por sedimentos litorâneos e marinhos de água rasa, em um intervalo definido como a base de um grande ciclo transgressivo-regressivo. Ocorre, então, uma rápida transgressão representada pelos folhelhos marinhos da Formação Ponta Grossa, que recobrem os arenitos da Formação Furnas, em contato gradual e sem interdigitações significativas, caracterizado pelo intervalo denominado "camadas de transição" (Petri, 1948 apud Assine et al., 1994). Também segundo Assine et al. (1994), podem ser distinguidas duas superfícies de inundação máxima nos folhelhos da Formação Ponta Grossa, que seriam parte do evento transgressivo global do Devoniano médio.

Lange e Petri (1967) recomendam o emprego da divisão da Formação Ponta Grossa em três membros: Jaguariaíva, Tibagi e São Domingos. O primeiro carrega formas fósseis eodevonianas, enquanto as duas superiores possuem conteúdo fossilífero mesodevoniano. Ainda segundo esses autores, a divisão em membros, estabelecida primordialmente de acordo com critérios litológicos, não pode ser aplicada a toda a extensão da bacia, uma vez que na parte central da Bacia do Paraná apenas uma sequência predominantemente pelítica é encontrada no intervalo devoniano, e pode ser classificada como Formação Ponta Grossa Indivisa. Nos estados de Goiás, Mato Grosso e Mato Grosso do Sul toda a sequência eodevoniana é representada pelos arenitos da Formação Furnas, e a primeira sequência pelítica sobre

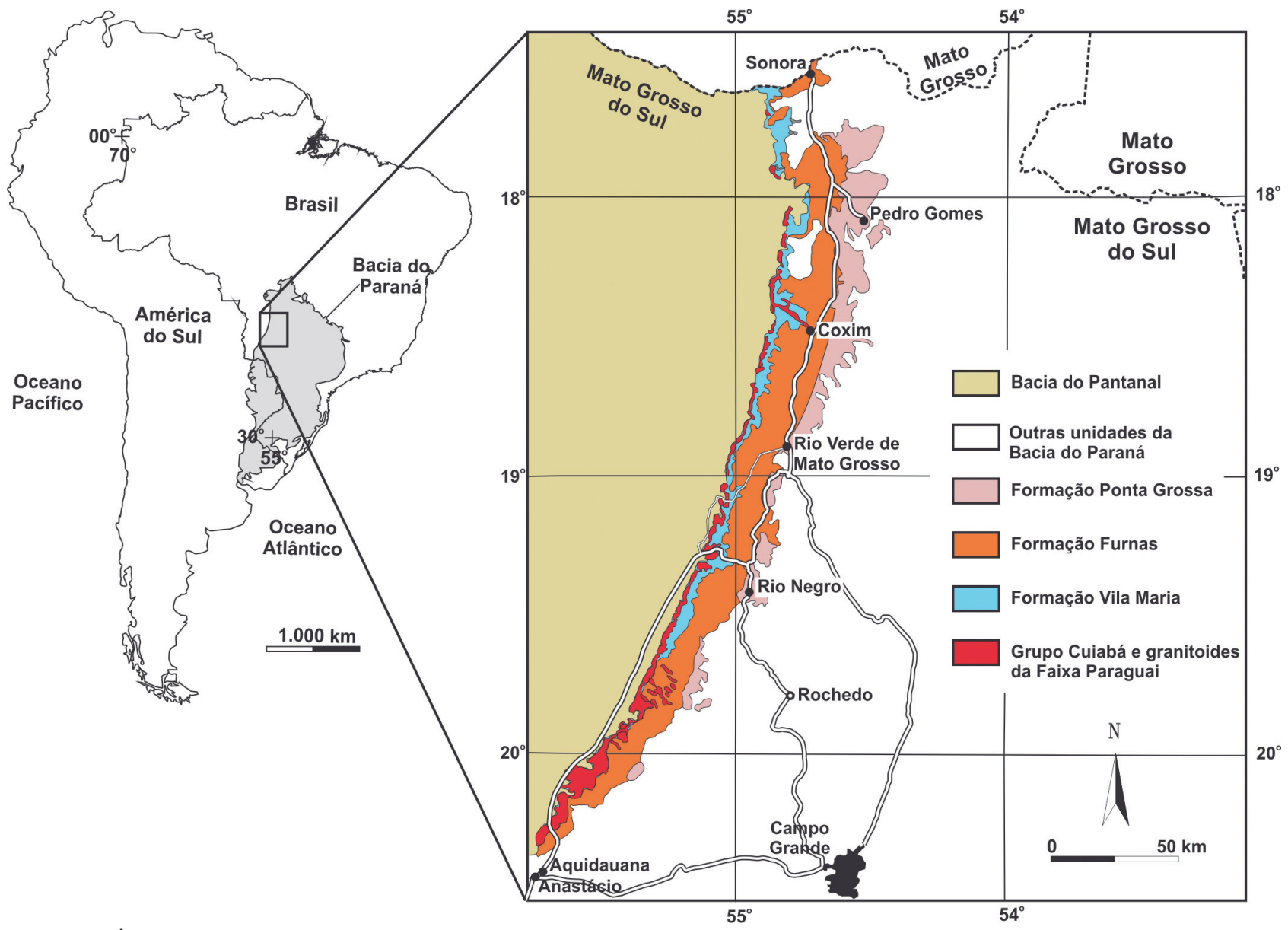

Figura 1. Área de afloramento das unidades devonianas da Bacia do Paraná no estado do Mato Grosso do Sul. 
essa formação já carrega formas de vida mesodevonianas, correlacionando biocronologicamente a Formação Ponta Grossa aflorante nessas regiões aos membros superiores descritos na seção tipo (membros Tibagi e São Domingos).

No intervalo emsiano-fammeniano (Eodevoniano superior a Neodevoniano superior), a Plataforma Sul-Americana localizava-se em altas latitudes, compreendidas entre $45^{\circ} \mathrm{e}$ $75^{\circ} \mathrm{S}$ (Copper, 1977, 2002; Caputo, 1985; Joachimski et al., 2009), implicando em condições climáticas subantárticas para os ambientes deposicionais que deram origem aos sedimentos das unidades da Bacia do Paraná desse intervalo de tempo. Essa região, nesse período, consistia em uma bacia desenvolvida em mar epicontinental raso, com ligação incipiente com o oceano. Grahn et al. (2010) estudaram a Subbacia do Alto Garças (noroeste da Bacia do Paraná) e consideraram que ela teve evolução distinta daquela observada nas seções-tipo da Formação Ponta Grossa (Sub-bacia do Apucarana, sul da Bacia do Paraná), com fácies indicativas de mar mais raso, consistindo, portanto, em um centro de sedimentação distinto. Essas mesmas condições de ambiente marinho mais raso para a Formação Ponta Grossa, interpretadas para a mesma unidade mais ao sul, podem também ser inferidas para as exposições estudadas no presente trabalho, em Rio Verde de Mato Grosso, Mato Grosso do Sul.

Montibeller e Zanardo (2014a, 2014b) reconheceram entre as rochas da Formação Ponta Grossa, aflorantes no município de Rio Verde de Mato Grosso, a presença de camadas constituídas predominantemente de apatita, não fossilíferas, descritas anteriormente em estudo realizado pela empresa DOCETO (Aita, 1978 apud Boggiani et al., 1998) nas regiões de Rio Verde de Mato Grosso - Rio Negro e em Rondonópolis, Mato Grosso, mas consideradas desprovidas de interesse econômico (Boggiani et al., 1998). No que concerne ao registro estratigráfico devoniano da Bacia do Paraná, até o momento não foram divulgados estudos que indiquem a presença de acumulações fosfáticas não associadas diretamente a restos fósseis, e mesmo a presença de partes fosfáticas preservadas de organismos não constitui concentrações significativas de $\mathrm{P}_{2} \mathrm{O}_{5}$ nas sequências pelíticas da Formação Ponta Grossa.

Segundo Bentor (1980), rochas sedimentares com conteúdo de fosfatos maior que o usual — maior que $5 \%$ — são a definição clássica de fosforitas. Diversos autores utilizam a composição química e a textura de fosforitas como critérios para avaliação das condições paleoclimáticas/paleoambientais das bacias em que ela se formaram (Ilyin, 1998; Hüneke, 2006; Dypvik e Zakharov, 2010; Garnit et al., 2012, entre outros) ou para a identificação de modelos fosfogenéticos (Föllmi, 1996; Fazio et al., 2007; Filippelli, 2011).

Assim, a presença de camadas fosfáticas em rochas sedimentares marinhas pode representar um marco estratigráfico na Bacia do Paraná e um indicador de paleoambiente pouco comum, no qual mecanismos localizados permitiram a concentração de $\mathrm{P}_{2} \mathrm{O}_{5}$.
Este trabalho teve como objetivo apresentar dados petrográficos e geoquímicos de camadas fosfáticas registrados por Montibeller e Zanardo (2014a, 2014b) em meio aos folhelhos atribuídos à Formação Ponta Grossa, no estado do Mato Grosso do Sul, visando contribuir para discussões acerca das condições paleoambientais dessa unidade na região estudada.

\section{MATERIAIS E MÉTODOS}

As camadas fosfáticas foram identificadas, a princípio, em uma frente de lavra de argila (denominada, neste trabalho, mina M1), utilizada como matéria-prima para a indústria cerâmica que se desenvolve na região. Sendo assim, foram visitadas diversas frentes de lavra (denominadas de M1, M2, M3, M4 e M5), com exposições correlatas, nas quais foram localizadas camadas endurecidas fosfáticas em meio aos folhelhos cinzas a pretos da Formação Ponta Grossa, verificando sua posição estratigráfica e sua continuidade. Uma vez localizadas, essas camadas foram descritas e amostradas para análise. As amostras foram encaminhadas para a confecção de seções delgadas e polidas, com espessura aproximada entre 30 e $60 \mu \mathrm{m}$, com e sem lamínula. Os estudos microscópicos foram realizados à luz transmitida e refletida, em microscópio petrográfico da marca Zeiss (Axioscope A1), com aumentos de $25,100,200,500$ e 1.000 vezes, e em microscópio eletrônico de varredura (MEV), com espectroscopia de energia dispersiva (EDS) da marca Jeol (modelo JSM-6010LA), com imageamento em BSE (backs cattered electrons - elétrons retroespalhados) e SEI (secondary electron image — imagem de elétrons secundários).

Para a identificação mineral das amostras, foi realizada difratometria de raios $\mathrm{X}$ em lâminas de material pulverizado (rocha total), em difratômetro de raios X da marca PANalytical EMPYREAN, com medidas realizadas utilizando radiação $\mathrm{CuK} \alpha 1$ (WL $=1,54056 \AA$ ), e filtro de Ni. O ângulo $2 \theta$ de início foi de $3^{\circ}$ e de término foi de $67^{\circ}$, com passo de 5 " e tamanho do passo de $0,02^{\circ}$. Ao difratômetro foi acoplado módulo acelerador $\mathrm{X}^{\prime}$ Celerator, que reduziu o tempo de análise. O tempo total de análise foi de 3'08', e a corrente empregada de $30 \mathrm{~mA}$ a uma voltagem de $40 \mathrm{kV}$. Os difratogramas gerados foram interpretados por meio do software X'Pert High Score Plus, com base de dados ICDD PDF2.

Parte de cada amostra laminada foi enviada para análises químicas (rocha total), executadas pelo Laboratório Acme (Analytical Laboratories LTD, Vancouver, Canadá), sendo os elementos maiores analisados por espectrometria de emissão atômica por plasma acoplado indutivamente (inductively coupled plasma optical emission spectrometry - ICP-OES), após fusão utilizando metaborato/tetraborato de lítio e digestão em ácido nítrico diluído, e a perda ao fogo (LOI) determinada pela diferença de peso da amostra antes e depois do aquecimento a $1.000^{\circ} \mathrm{C}$ por quatro horas. 
Os elementos-traços e os elementos terras raras (ETR) foram analisados por espectrômetro de massa em plasma indutivamente acoplado (inductively coupled plasma mass spectrometry - ICP-MS), após fusão utilizando metaborato/tetraborato de lítio e digestão em ácido nítrico, sendo que para os metais $\mathrm{Cu}, \mathrm{Ni}, \mathrm{Pb}$ e $\mathrm{Zn}$ a digestão foi por água régia. $\mathrm{O}$ tratamento dos dados geoquímicos e a construção de diagramas foram realizados com emprego do programa PETROGRAPH versão 2 beta dic2007 (Petrelli et al., 2005).

\section{DESCRIÇÃO DAS OCORRÊNCIAS}

\section{Aspectos da ocorrência nas frentes de lavra}

No município de Rio Verde de Mato Grosso, a Formação Ponta Grossa apresenta as melhores exposições em frentes de lavra de argilas para as indústrias cerâmicas da região, nas quais se observa, em geral, a seguinte sucessão de litologias, da base para o topo (Figura 2):

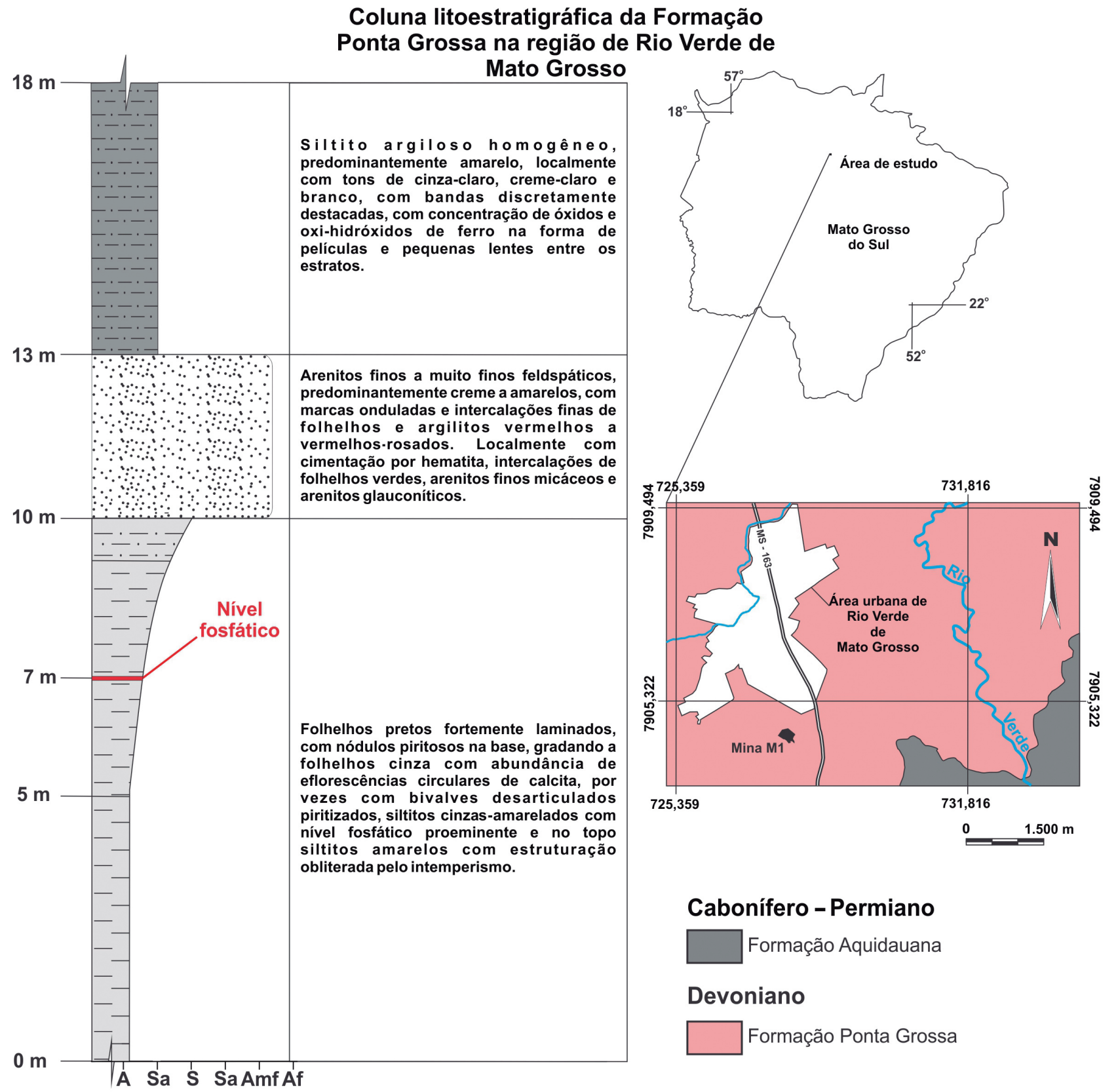

Figura 2. Coluna litoestratigráfica esquemática da Formação Ponta Grossa na região de Rio Verde de Mato Grosso. Modificado de Montibeller et al. (2017). 
1. folhelhos cinzas a pretos, carbonáticos ou não, compostos em geral por filossilicatos diversos ( $35-75 \%)$, carbonatos de cálcio (calcita) e de ferro (siderita) $(0-20 \%)$, quartzo e feldspato potássico detríticos $(10-50 \%)$, com presença de óxidos/hidróxidos de ferro $( \pm 5 \%)$ e traços de outros minerais detríticos (turmalina, zircão e opacos);

2. arenitos muito finos, arcosianos, constituídos por quartzo (30-54\%), feldspato detrítico $(35-45 \%)$, predominando feldspato potássico e muito raramente plagioclásios, micas detríticas (predominando muscovita e biotita subordinada) $(3-10 \%)$, minerais opacos e hidróxidos de ferro $( \pm 5 \%)$, illita/clorita neoformadas $( \pm 1 \%)$ e traços de outros minerais detríticos (zircão, turmalina e rutilo);

3. siltitos e argilitos amarelos homogêneos, em geral alterados, com laminação incipientemente preservada, compostos por argilominerais (interestratificados montmorillonita/clorita, muscovita/illita e caulinita) e pequenas proporções de quartzo e feldspato potássico.
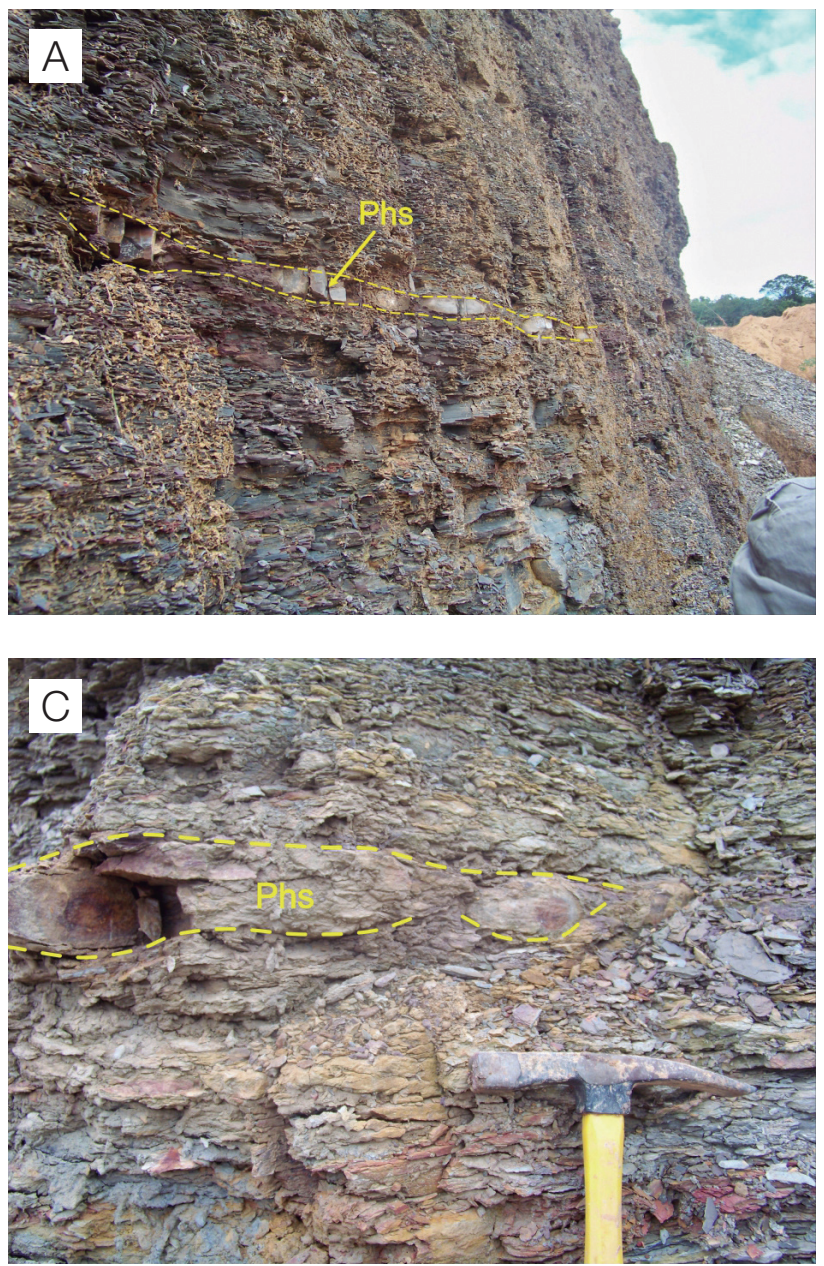

Phs: camada de rocha fosfática (fosforita).

Figura 3. Modo de ocorrência da camada fosfática encontrada nas minas M1, M2 e M3 em Rio Verde de Mato Grosso, Mato Grosso do Sul. Nota-se o aspecto descontínuo e de estrutura sutilmente laminada a nodular, com espessuras variadas.
Esses conjuntos litológicos possuem particularidades que são descritas na Figura 2. Dados petrográficos e litoquímicos das rochas que compõem essa sequência podem ser encontrados em Montibeller e Zanardo (2014b), Montibeller (2015) e Montibeller et al. (2017). A mina denominada de M1 (Figura 2) apresenta a sucessão litológica da Formação Ponta Grossa mais completa encontrada durante as atividades de campo.

As rochas fosfáticas ocorrem como camadas destacadas nos afloramentos (Figura 3), descontínuas, intercaladas nos folhelhos cinzas (Figuras 3A e 3B), com espessuras variando de 5 a $20 \mathrm{~cm}$, com estrutura sutilmente laminada, às vezes com estrutura interna nodular (Figura 3C), e textura compacta (Figura 3D). Possuem cor cinza-escura com matiz marrom avermelhada, podendo conter fraturas ou planos de rompimento preenchidos por carbonatos e filmes de oxi-hidróxidos de manganês.
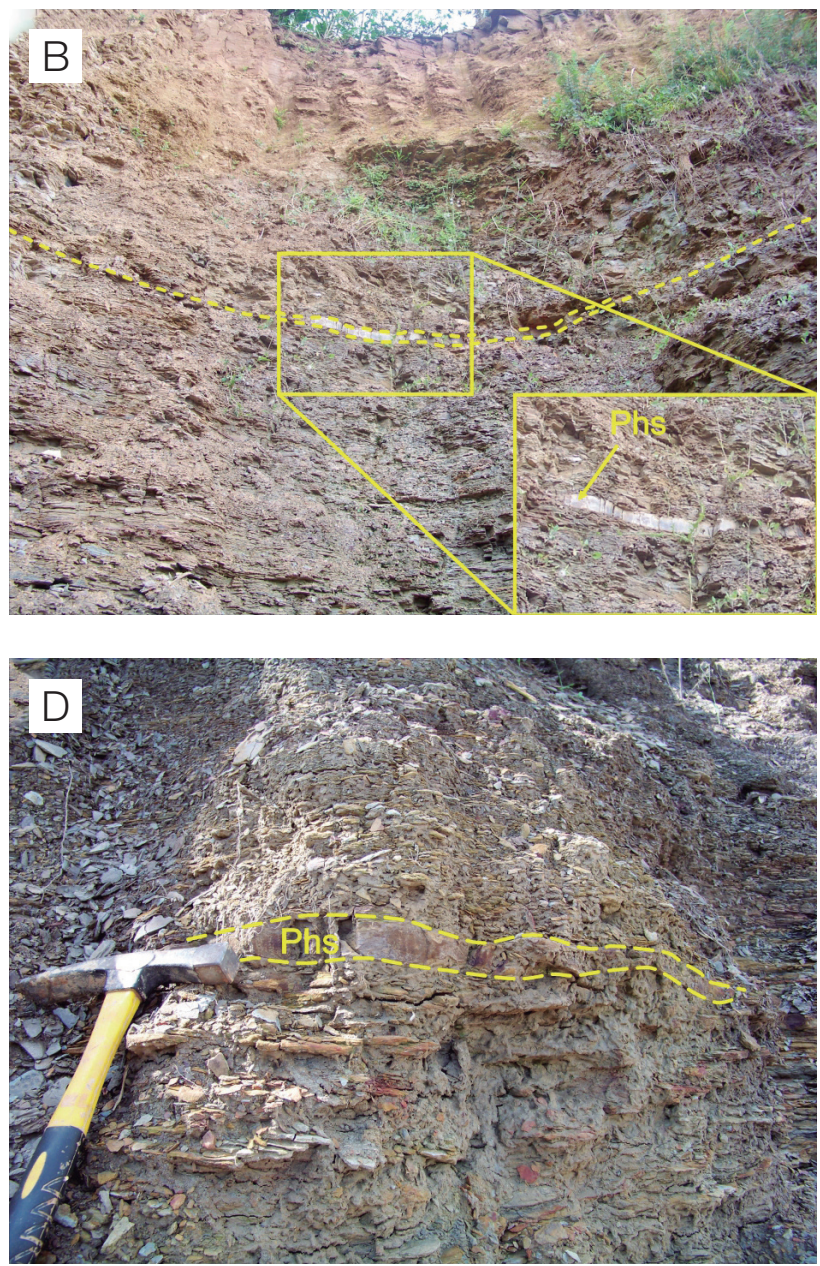


\section{Petrografia e microscopia eletrônica}

Petrograficamente, as fosforitas apresentam estrutura sutilmente laminada, marcada, sobretudo, pela disposição levemente orientada de palhetas delgadas e minúsculas de filossilicatos (muscovita/sericita detríticas, argilominerais detríticos e possivelmente illita diagenética) $( \pm 15 \%)$ com comprimentos normalmente inferiores a $60 \mu \mathrm{m}$, raramente atingindo $90 \mu \mathrm{m}$, constituindo em alguns domínios difusas trilhas paralelas (Figura 4). A textura é lutítica, formada por uma massa criptocristalina de fosfato (carbonato-fluorapatita) $( \pm 60 \%)$ que engloba os filossilicatos, e por pontuações formadas por agregados subesféricos a elipsoidais de óxidos e hidróxidos de ferro e manganês $( \pm 15 \%)$ de dimensões médias
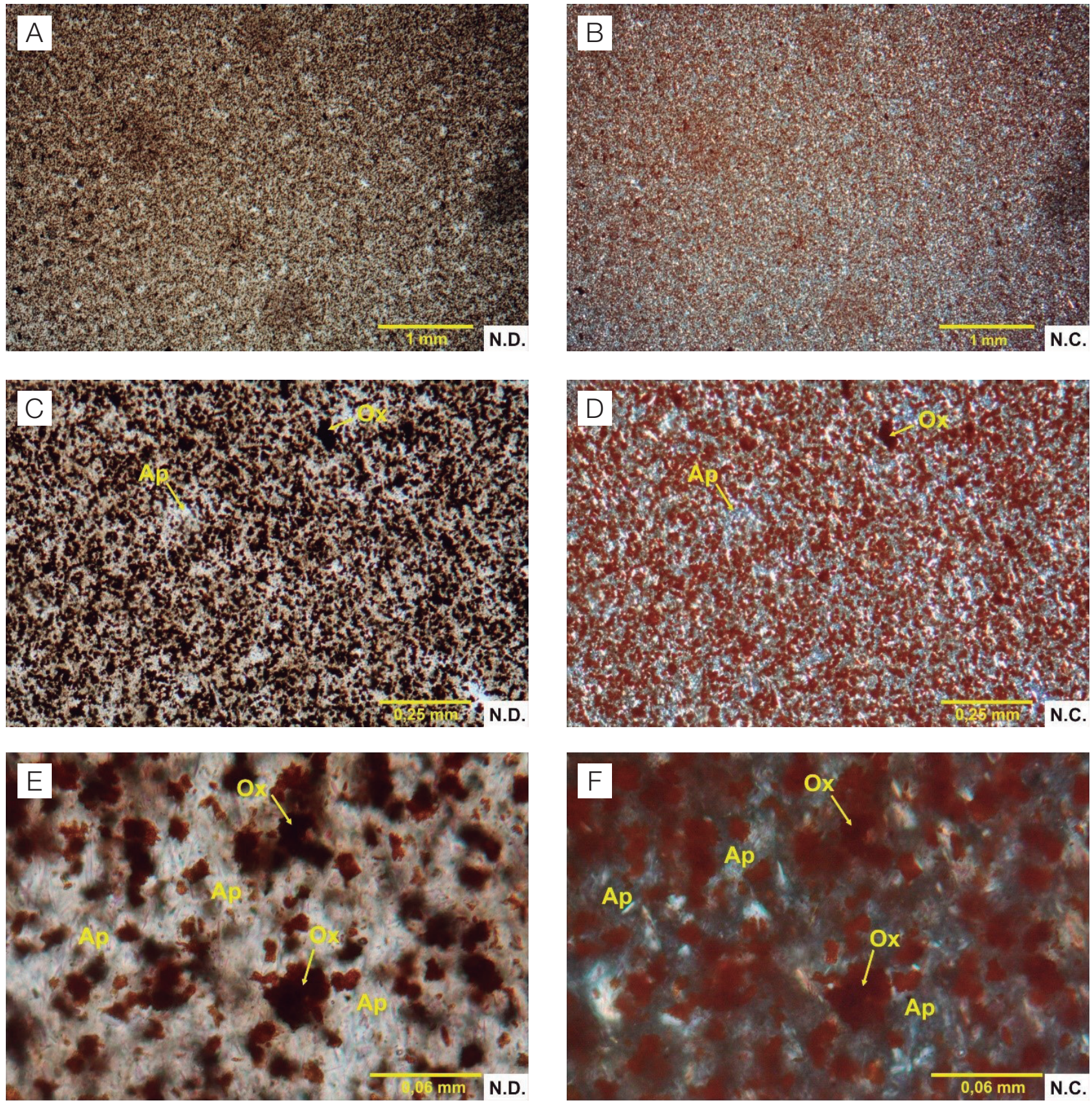

Ap: carbonato-fluorapatita; Ox: óxidos e oxi-hidróxidos.

Figura 4. (A-F) Fotomicrografias à luz transmitida de lâminas delgadas usando polarizadores paralelos (N.D.) e cruzados (N.C.); (A, B) textura lutítica da camada fosfática; (C, D) detalhe da textura, sem nenhuma evidência de estruturas biogênicas; $(\mathrm{E}, \mathrm{F})$ detalhe dos óxidos e dos hidróxidos, constituídos por aglomerados de minúsculos cristais, em sua maioria não opacos. 
da ordem de $15 \mu \mathrm{m}$, podendo atingir cerca de $80 \mu \mathrm{m}$. Esses agregados de óxidos e hidróxidos são constituídos por minúsculas pontuações, da ordem de $1 \mu \mathrm{m}$ ou menores, e formando, principalmente, aglomerados de minúsculos cristais, com formas arredondadas, porém com pontas, gerando aspecto semelhante a estrelas irregulares. Também são observados minúsculos cristais e/ou agregados microcristalinos, irregulares a elipsoidais, levemente orientados, de carbonato $(<5 \%)-$ normalmente inferiores a $30 \mu \mathrm{m}$ - e poucos grãos detríticos de quartzo e feldspatos $(<5 \%)$ dispersos pela lâmina, com granulação inferior a $30 \mu \mathrm{m}$. Ao microscópio petrográfico não foram observadas feições indicativas de algas, restos fósseis ou de estruturas orgânicas. O litotipo pode ser classificado como uma fosforita (NF) não bioclástica ferruginosa rica em filossilicatos detríticos. Segundo a classificação de Slansky (1986), a NF pode ser denominada de microfosfalutito, com cerca de $15 \%$ de endogangue (minerais que são diretamente associados à precipitação de fosfatos) de óxidos e hidróxidos, e aproximadamente $15 \%$ de exogangue (minerais não fosfáticos que não se associam com a precipitação dos fosfatos) clástica argilosa.

Em análise por MEV, realizada em material pulverizado e em duas seções delgadas, todas provenientes de diferentes pontos de coleta de material, nota-se que a camada fosfática é composta por uma massa criptocristalina de fosfatos, associada a cristais detríticos dispersos caoticamente e com minúsculas pontuações mais densas ricas em ferro e manganês (Figura 5), o que é confirmado por análise pontual com o uso de EDS.
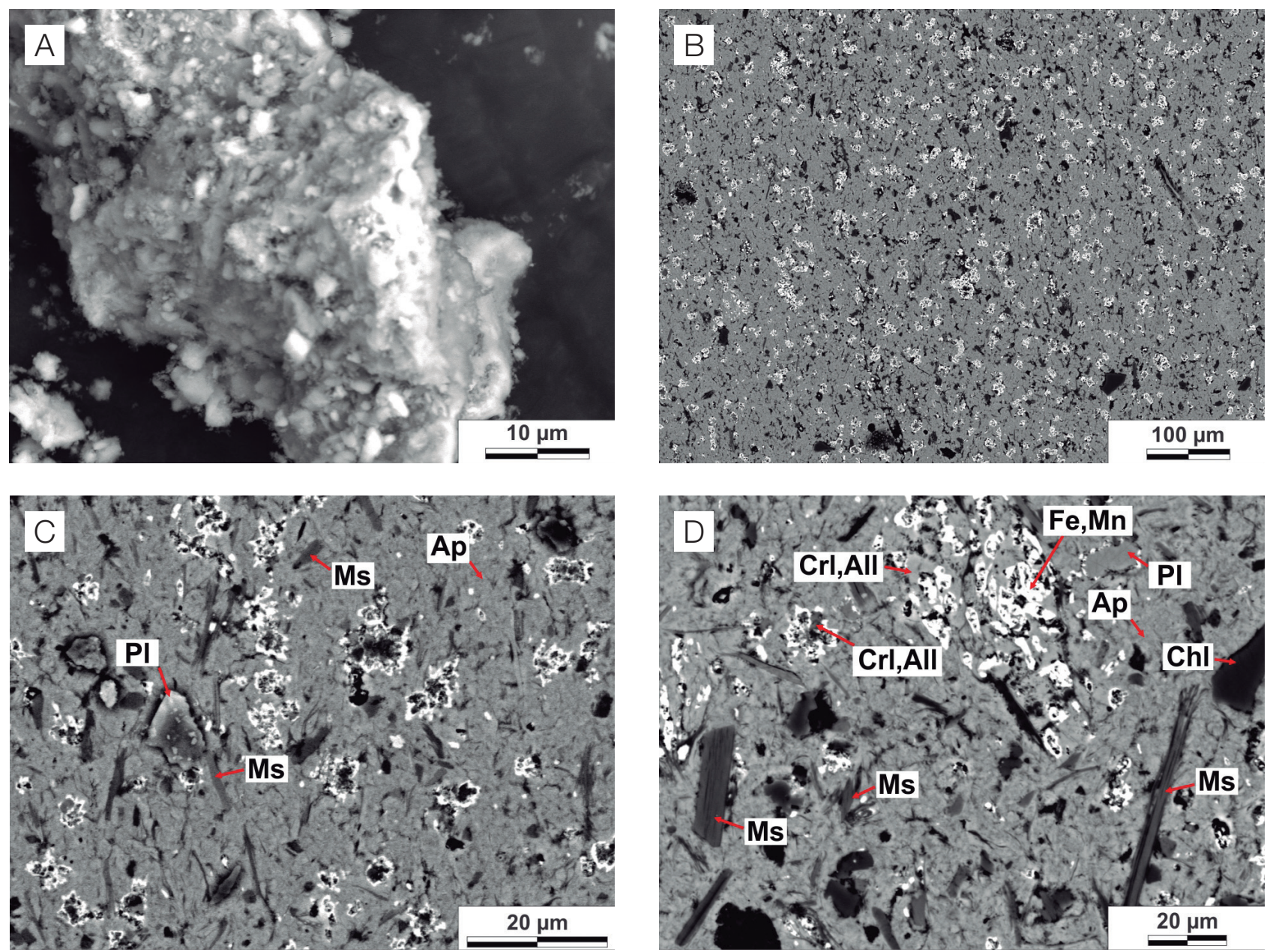

Ap: carbonato-fluorapatita; Ms: muscovita (provavelmente rica em termos fengíticos); Pl: plagioclásio; Chl: clorita; Fe, Mn: intercrescimento de oxi-hidróxidos de ferro e manganês; Crl, All: associação de minerais quimicamente semelhantes aos grupos da crandallita e da alluardita.

Figura 5. Imagens de elétrons retroespalhados obtidas em seções polidas. (A) Aspecto dos aglomerados de cristais, em que pode ser observado carbonato-fluorapatita na forma de uma massa irregular microcristalina, envolvendo cristais de outros minerais granulares e micáceos; (B) imagem geral da textura observada na seção, destacando a ausência de estruturas que possam sugerir origem biogênica; $(C, D)$ detalhes das amostras em seção delgada, em que é possível observar os cristais de minerais detríticos imersos na matriz irregular composta por carbonato-fluorapatita. Destaque para a imagem $\mathrm{D}$, em que são identificadas as aglomerações de oxi-hidróxidos, que em análise por espectroscopia de energia dispersiva aparentam ser constituídos por intercrescimento entre oxi-hidróxidos de ferro e manganês, associados a fosfatos dos grupos da crandallita e da alluardita. 
A análise detalhada das pontuações mais densas por meio da geração de mapas composicionais por EDS (Figura 6) mostra que essas se tratam de óxidos predominantemente de ferro com alguma contribuição de manganês, imersos em matriz rica em fósforo e associada a silicatos detríticos.

\section{Difratometria de raios $X$}

Por meio da difratometria de raios X, a composição mineralógica obtida para as rochas fosfáticas é dominada por minerais do grupo da apatita, predominantemente carbonato-fluorapatita (Figura 7). Em geral, as fosforitas apresentam certo acamadamento ou envelopamento, e carbonato-fluorapatita é mais comum nas camadas mais externas dos nódulos, enquanto os núcleos podem apresentar carbonato-hidroxilapatita ou simplesmente apatita. Não foram observadas, nos difratogramas, tendências significativas a fases não cristalinas, ou incipientemente cristalizadas, de fosfatos de cálcio hidratados (colofano).

\section{Geoquímica}

\section{Elementos maiores, menores e traços}

As amostras de fosforitas (Tabelas $1 \mathrm{e} 2$ ) possuem teores de $\mathrm{P}_{2} \mathrm{O}_{5}$ entre 12,96 e $23,35 \%$, e teores de $\mathrm{CaO}$ entre 19,85 e $33,04 \%$, que correspondem a, aproximadamente, 30 a $60 \%$ de fosfato de cálcio, com excedente de cerca de 2 a $6 \%$ de $\mathrm{CaO}$ disponível para compor a estrutura de outros minerais não fosfáticos.

O teor de $\mathrm{SiO}_{2}$ nas amostras varia de 13,60 a $26,79 \%$; de $\mathrm{Al}_{2} \mathrm{O}_{3}$, entre 6,87 e $11,04 \%$; de $\mathrm{K}_{2} \mathrm{O}$, entre 0,86 e 1,47\%; e de $\mathrm{Na}_{2} \mathrm{O}$, entre 0,33 e $0,53 \%$. O MgO varia entre 0,60 e $2,35 \%$, o $\mathrm{Fe}_{2} \mathrm{O}_{3}$ entre 6,56 e $14,71 \%$, o $\mathrm{TiO}_{2}$ entre 0,30 e $0,51 \%$ e o $\mathrm{MnO}$ entre 0,07 e $0,33 \%$.

Em diagramas binários do tipo $\mathrm{M}$ versus $\mathrm{P}_{2} \mathrm{O}_{5}$ (Figura 8), em que $\mathrm{M}$ representa elementos maiores e alguns traços selecionados, $\mathrm{CaO}, \mathrm{Na}_{2} \mathrm{O}, \mathrm{Ba}$ e $\mathrm{Sr}$ apresentam boa correlação
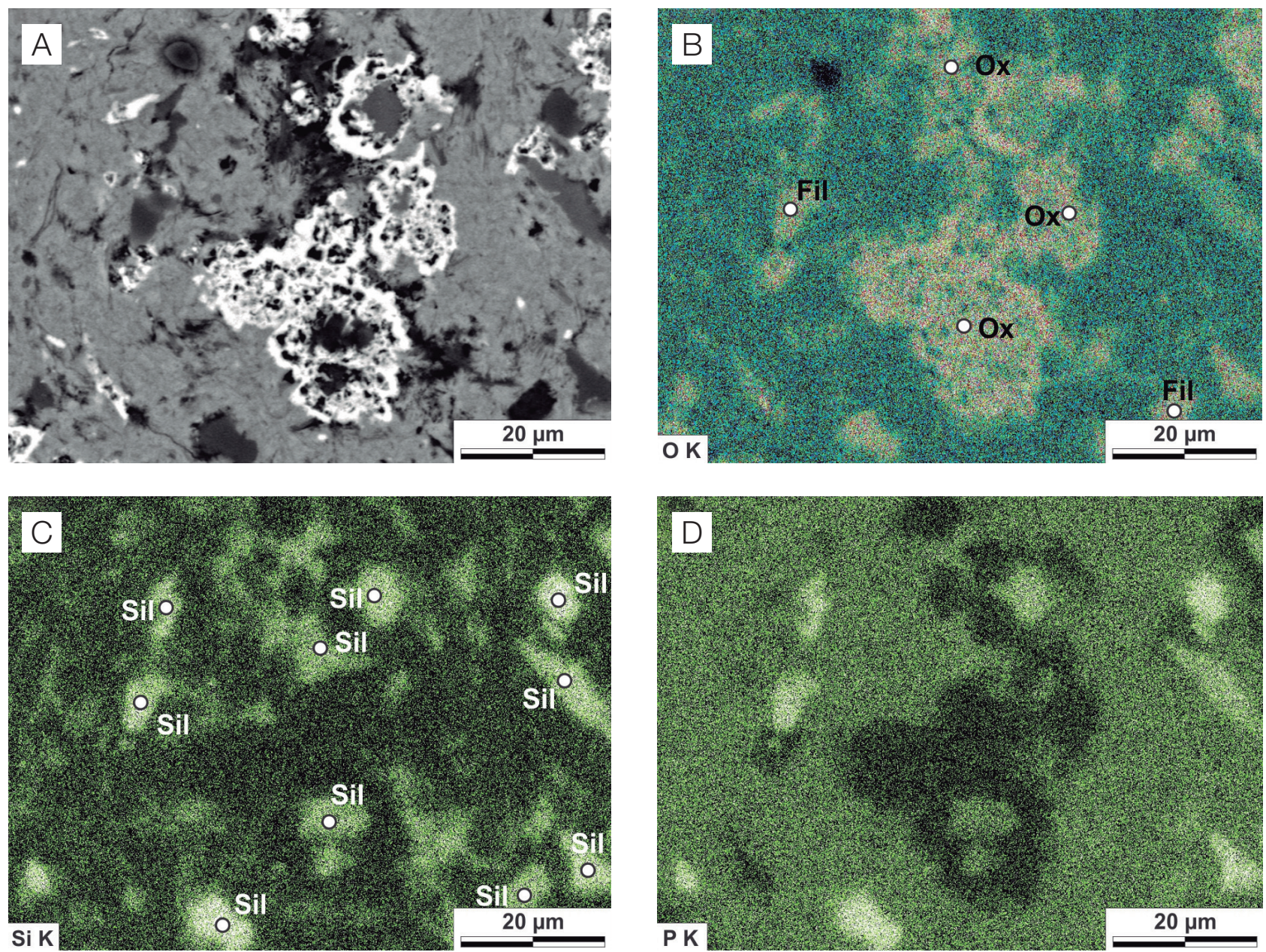

Fil: filossilicatos; Ox: oxi-hidróxidos; Sil: silicatos.

Figura 6. Mapa da distribuição de $\mathrm{O}(\mathrm{B}), \mathrm{Si}(\mathrm{C})$ e $\mathrm{P}(\mathrm{D})$ nas amostras da camada fosfática analisadas, com ênfase para as pontuações densas $(A)$ que podem ser observadas na seção. 
positiva com o $\mathrm{P}_{2} \mathrm{O}_{5}$, enquanto $\mathrm{SiO}_{2}, \mathrm{TiO}_{2}, \mathrm{Al}_{2} \mathrm{O}_{3}, \mathrm{~K} 2 \mathrm{O}, \mathrm{Rb}$, $\mathrm{Zr}$ e Th apresentam fraca correlação negativa com o $\mathrm{P}_{2} \mathrm{O}_{5}$. Os elementos $\mathrm{Fe}_{2} \mathrm{O}_{3} \mathrm{~T}$ e $\mathrm{MnO}$, apesar de não apresentarem boa correlação com o $\mathrm{P}_{2} \mathrm{O}_{5}$, apresentam comportamentos semelhantes com relação a este. Não é observada correlação entre Hf e U com relação ao $\mathrm{P}_{2} \mathrm{O}_{5}$.

Em diagramas binários do tipo $\mathrm{M}$ versus $\mathrm{SiO}_{2}$ (Figura 9), as amostras da camada fosfática são comparadas com os folhelhos cinzas-escuros a pretos nos quais estão intercalados. Nas fosforitas, os elementos $\mathrm{TiO}_{2}, \mathrm{Al}_{2} \mathrm{O}_{3}, \mathrm{~K}_{2} \mathrm{O}, \mathrm{Rb}$, $\mathrm{Zr}$, Hf e Th apresentam boa correlação positiva com o $\mathrm{SiO}_{2}$, enquanto $\mathrm{CaO}, \mathrm{Na}_{2} \mathrm{O}$ e $\mathrm{P}_{2} \mathrm{O}_{5}$ apresentam fraca correlação negativa em relação a $\mathrm{SiO}_{2}$. Nesses diagramas, em comparação aos folhelhos, a rocha fosfática apresenta menores conteúdos em $\mathrm{TiO}_{2}, \mathrm{Al}_{2} \mathrm{O}_{3}, \mathrm{~K}_{2} \mathrm{O}, \mathrm{Rb}, \mathrm{Zr}$, Hf e Th; predominam conteúdos menores em $\mathrm{MgO}$; conteúdos semelhantes em $\mathrm{Fe}_{2} \mathrm{O}_{3} \mathrm{~T}, \mathrm{Ba}$, e U; conteúdos geralmente maiores em $\mathrm{MnO}$; e conteúdos sistematicamente maiores em $\mathrm{CaO}, \mathrm{Na}_{2} \mathrm{O}, \mathrm{P}_{2} \mathrm{O}_{5}$ e Sr. Nota-se que, enquanto as amostras fosfáticas apresentam correlação positiva entre $\mathrm{Al}_{2} \mathrm{O}_{3}$ e Th e $\mathrm{SiO}_{2}$, as amostras dos folhelhos apresentam correlação negativa entre esses elementos e o $\mathrm{SiO}_{2}$.

\section{Elementos terras raras}

ANF possui alta concentração de ETR em relação à média da composição química de folhelhos americanos (North America Shale Composite - NASC, Gromet et al., 1984) e à média da crosta continental superior (Upper Continental Crust UCC, Rudnick e Gao, 2003) $\left(\Sigma \mathrm{ETR}_{\mathrm{NF}}=669,80\right.$ a 2345,60 ; $\left.\Sigma \mathrm{ETR}_{\mathrm{NASC}}=154,50 ; \Sigma \mathrm{ETR}_{\mathrm{UCC}}=148,10\right)$. Quando comparados com os folhelhos hospedeiros (Montibeller et al., 2017) normalizados pelo NASC, as amostras de rocha fosfática possuem teores em ETR até 30 vezes mais enriquecidos (Figura 10A). Essa rocha possui enriquecimento em ETR médios ( $\mathrm{Sm}, \mathrm{Eu}, \mathrm{Gd}$ e $\mathrm{Tb}$ ), apresentando baixa razão $\mathrm{La}_{\mathrm{N}} / \mathrm{Eu}_{\mathrm{N}}(0,28$ a 0,52$)$ e alta razão $\mathrm{Gd}_{\mathrm{N}} / \mathrm{Lu}_{\mathrm{N}}(1,84$ a 3,56) normalizadas pelo NASC, enquanto a razão $\mathrm{La}_{\mathbb{N}} / \mathrm{Lu}_{\mathrm{N}}$ permanece próxima de $1(0,79$ a 0,96$)$. O padrão de distribuição apresenta forma abaulada em relação ao NASC e em relação ao valor médio de fosforitas marinhas de Magdalena Bay (Oceano Pacífico, Baja California Sur, México) apresentado por Goldberg et al. (1963), e mostra ligeiro enriquecimento em ETR médios também com relação a estas, além de leve enriquecimento em Ce (Figura 7B).

\section{DISCUSSÃO}

Segundo Bentor (1980), o fósforo é um elemento traço raro em águas oceânicas, com concentração média de 70 ppb. Quando essas águas estão próximas à superfície, grande parte do fósforo é removida por atividade biológica, e em presença de matéria orgânica, as concentrações de fósforo podem se elevar a até $100 \mathrm{ppb}$ em profundidades entre 200 e $400 \mathrm{~m}$. O intervalo crítico de $\mathrm{pH}$ entre 7 e 8 é responsável

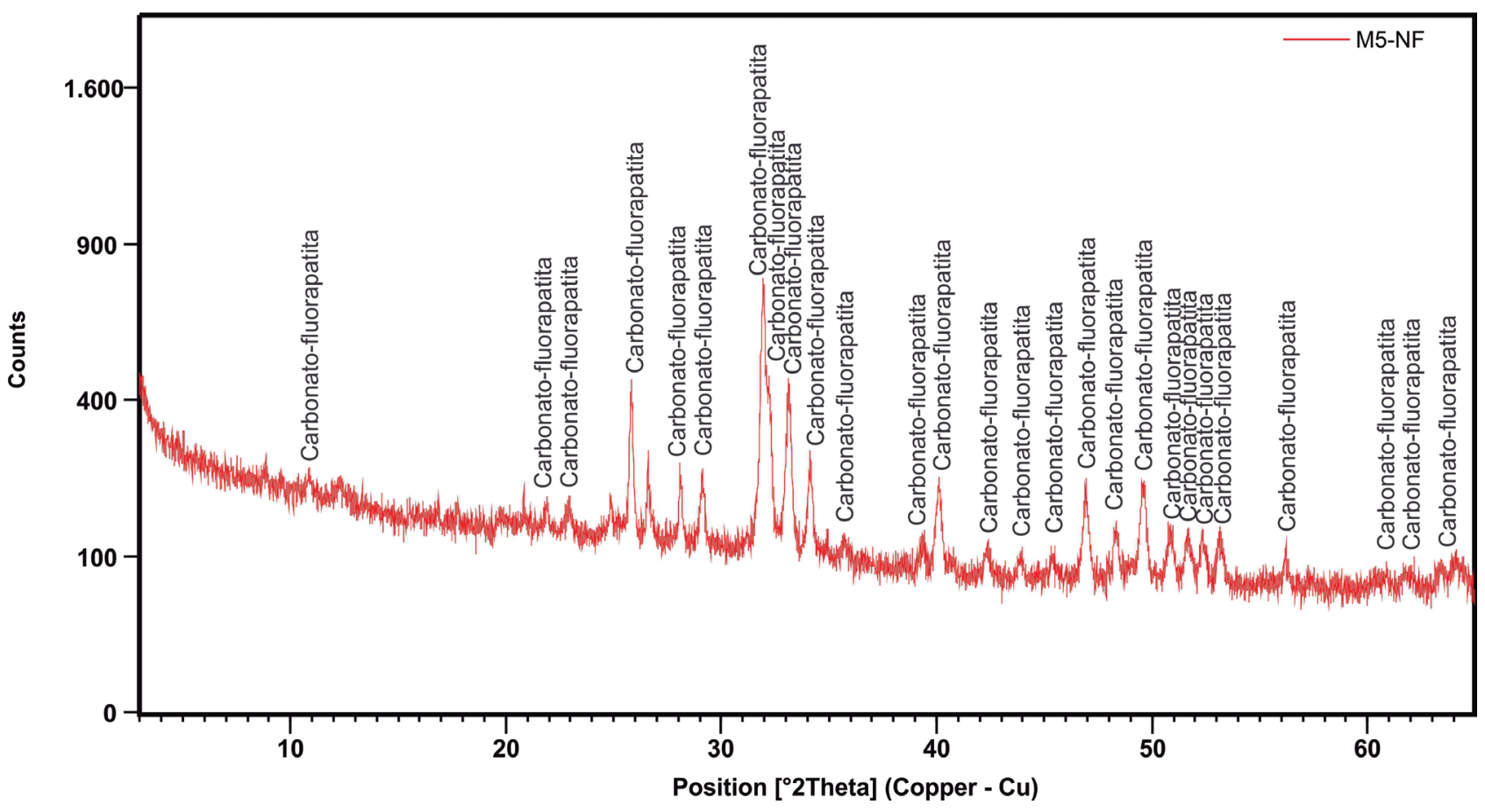

Figura 7. Difratograma representativo dos resultados obtidos para as amostras de rochas fosfáticas em Rio Verde de Mato Grosso, Mato Grosso do Sul. Amostra M5-NF. 
Tabela 1. Análises químicas de elementos maiores, menores e traços para as amostras de camada fosfática em Rio Verde de Mato Grosso, Mato Grosso do Sul.

\begin{tabular}{|c|c|c|c|c|c|c|c|c|}
\hline Amostra & RV-M1-3 ${ }^{a}$ & RV-M1-4 ${ }^{a}$ & RV-M2-2 & RV-M3-2 & RV-M3-2B & RV-M3-3 & RV-M3-9A & RV-M5-1B \\
\hline $\mathrm{SiO}_{2}$ & 14,45 & 14,66 & 20,35 & 13,06 & 13,68 & 26,79 & 21,83 & 22,91 \\
\hline $\mathrm{TiO}_{2}$ & 0,31 & 0,32 & 0,44 & 0,30 & 0,31 & 0,51 & 0,45 & 0,45 \\
\hline $\mathrm{Al}_{2} \mathrm{O}_{3}$ & 7,40 & 7,14 & 8,67 & 6,87 & 7,27 & 8,96 & 11,04 & 10,48 \\
\hline $\mathrm{Fe}_{2} \mathrm{O}_{3} \mathrm{~T}$ & 11,61 & 10,79 & 6,56 & 13,60 & 11,84 & 13,21 & 14,71 & 8,67 \\
\hline $\mathrm{MnO}$ & 0,22 & 0,23 & 0,07 & 0,22 & 0,33 & 0,17 & 0,29 & 0,11 \\
\hline $\mathrm{MgO}$ & 0,75 & 0,73 & 0,60 & 0,71 & 0,61 & 0,70 & 2,35 & 0,82 \\
\hline $\mathrm{CaO}$ & 32,85 & 32,68 & 31,58 & 32,70 & 33,04 & 23,50 & 19,85 & 26,94 \\
\hline $\mathrm{Na}_{2} \mathrm{O}$ & 0,48 & 0,50 & 0,46 & 0,52 & 0,53 & 0,38 & 0,33 & 0,50 \\
\hline $\mathrm{K}_{2} \mathrm{O}$ & 1,01 & 0,95 & 1,39 & 0,86 & 0,88 & 1,47 & 1,36 & 1,34 \\
\hline $\mathrm{P}_{2} \mathrm{O}_{5}$ & 21,91 & 22,93 & 22,07 & 23,35 & 23,21 & 16,21 & 12,96 & 18,52 \\
\hline LOI & 8,70 & 8,70 & 7,40 & 7,40 & 7,80 & 7,70 & 14,50 & 8,70 \\
\hline$\Sigma_{o x}$ & 99,69 & 99,63 & 99,59 & 99,59 & 99,50 & 99,60 & 99,67 & 99,44 \\
\hline TOT/C & 1,10 & 1,20 & 0,81 & 0,82 & 0,84 & 0,60 & 3,33 & 0,68 \\
\hline TOT/S & 0,25 & 0,31 & 0,22 & 0,43 & 0,35 & 0,29 & 0,33 & 0,33 \\
\hline Sc & 18,00 & 18,00 & 18,00 & 23,00 & 25,00 & 21,00 & 20,00 & 22,00 \\
\hline V & 130,00 & 136,00 & 132,00 & 146,00 & 162,00 & 156,00 & 196,00 & 150,00 \\
\hline $\mathrm{Cr}$ & 164,21 & 61,58 & 61,58 & 54,74 & 54,74 & 68,42 & 68,42 & 68,42 \\
\hline Co & 15,20 & 10,40 & 11,20 & 13,30 & 13,20 & 24,30 & 11,70 & 16,60 \\
\hline $\mathrm{Ni}$ & 19,70 & 15,80 & 26,50 & 19,00 & 15,30 & 23,70 & 22,20 & 24,60 \\
\hline $\mathrm{Cu}$ & 13,10 & 12,90 & 16,50 & 16,20 & 14,80 & 23,40 & 15,20 & 15,30 \\
\hline $\mathrm{Zn}$ & 39,00 & 38,00 & 66,00 & 43,00 & 36,00 & 39,00 & 55,00 & 83,00 \\
\hline $\mathrm{Rb}$ & 35,50 & 37,90 & 52,40 & 36,90 & 37,90 & 60,00 & 54,10 & 55,20 \\
\hline Cs & 3,60 & 2,80 & 3,70 & 2,60 & 3,30 & 3,40 & 4,20 & 4,60 \\
\hline $\mathrm{Sr}$ & 911,90 & 1031,50 & 905,70 & 1071,30 & 1117,20 & 637,30 & 518,90 & 710,60 \\
\hline $\mathrm{Ba}$ & 372,00 & 402,00 & 624,00 & 566,00 & 750,00 & 346,00 & 279,00 & 450,00 \\
\hline Y & 270,50 & 348,40 & 326,50 & 362,60 & 445,20 & 403,20 & 365,60 & 732,60 \\
\hline $\mathrm{Zr}$ & 57,90 & 77,70 & 103,80 & 73,10 & 79,10 & 245,90 & 93,00 & 123,70 \\
\hline $\mathrm{Hf}$ & 1,40 & 1,60 & 2,40 & 1,40 & 1,60 & 5,60 & 2,20 & 2,20 \\
\hline $\mathrm{Nb}$ & 4,40 & 6,60 & 8,60 & 6,10 & 6,30 & 9,70 & 8,40 & 8,80 \\
\hline $\mathrm{Ta}$ & 0,30 & 0,40 & 0,60 & 0,50 & 0,40 & 0,60 & 0,70 & 0,60 \\
\hline $\mathrm{Pb}$ & 11,70 & 7,00 & 10,20 & 8,60 & 10,30 & 172,30 & 13,40 & 10,30 \\
\hline Th & 6,10 & 6,20 & 7,70 & 5,60 & 5,80 & 9,10 & 8,10 & 7,20 \\
\hline U & 3,80 & 4,00 & 4,00 & 5,70 & 7,20 & 5,20 & 3,20 & 4,50 \\
\hline Ga & 8,10 & 9,80 & 11,20 & 8,40 & 9,40 & 10,80 & 13,00 & 12,40 \\
\hline $\mathrm{Be}$ & * & 1,00 & 2,00 & 4,00 & 3,00 & 2,00 & 2,00 & * \\
\hline W & 0,60 & 0,60 & 0,90 & 0,90 & 1,50 & 1,40 & 1,40 & 1,20 \\
\hline Sn & 1,00 & 1,00 & 2,00 & 1,00 & 1,00 & 2,00 & 2,00 & 2,00 \\
\hline Mo & 1,10 & 0,90 & 1,00 & 1,00 & 1,20 & 2,20 & 0,50 & 0,50 \\
\hline
\end{tabular}

TOT/C: análise total do conteúdo de carbono por Inductively Coupled Plasma Optical Emission Spectrometry (ICP-OES); TOT/S: análise total do conteúdo de enxofre por Inductively Coupled Plasma Optical Emission Spectrometry (ICP-OES); $\Sigma_{\text {ox }}$ somatório dos elementos maiores na forma de óxidos; LOI: Iossonignition (perda ao fogo); *valores abaixo do limite de detecção. 
pela dissolução dos fosfatos na forma dominante de $\left(\mathrm{HPO}_{4}\right)^{-2}$. Grandes quantidades de íons fosfato são liberadas à medida que sulfatos são reduzidos, em sedimentos ricos em matéria orgânica, mas se concentram nas águas intersticiais destes sedimentos, com concentração de até 7.500 ppb (Sholkovitz, 1973; Bentor, 1980).

Baturin (1982) descreveu as seguintes gêneses possíveis para concentrações de fosfatos em ambientes aquosos:

1. deposição a partir de detritos biogênicos e coprólitos;

2. deposição microbial e enzimática;

3. sorção e coprecipitação de fósforo com oxi-hidróxidos de manganês;

4. fosfatização de carbonatos;

5. precipitação de íons fosfato e partículas de fosfato coloidais eletricamente carregadas, em superfícies sólidas eletricamente ativas salientes, inclusive concreções pretéritas.
Para as rochas fosfáticas de Rio Verde de Mato Grosso, não há evidência de deposição por detritos biogênicos, fosfatização de carbonatos ou precipitação coloidal em rugosidades de fundo, restando como alternativas possíveis a deposição por atividade microbial e a coprecipitação de fósforo com oxi-hidróxidos de manganês.

Segundo Föllmi (1996), as possíveis fontes de fosfato sedimentar incluem fosfato liberado por atividade microbial a partir de matéria orgânica soterrada e a dessorção de fosfato por comportamento redox a partir de oxi-hidróxidos de ferro e manganês, enquanto o fosfato dissolvido na água do mar (ou em água de poros, como apresentado por Bentor, 1980) representaria uma fonte adicional. Como ambiente propício para a fosfogênese, Föllmi (1996) considera, principalmente, a interface água-sedimento, e em relação à estratigrafia de sequências, depósitos de fosfatos representariam, em geral, superfícies de inundação

Tabela 2. Análises químicas de elementos terras raras para as amostras de camada fosfática em Rio Verde de Mato Grosso, Mato Grosso do Sul.

\begin{tabular}{lcccccccc}
\hline Amostra & RV-M1-3 $^{\text {a }}$ & RV-M1-4 $^{\text {a }}$ & RV-M2-2 & RV-M3-2 & RV-M3-2B & RV-M3-3 & RV-M3-9A & RV-M5-1B \\
\hline $\mathrm{La}$ & 96,00 & 127,40 & 117,00 & 141,90 & 158,90 & 141,20 & 136,30 & 245,30 \\
$\mathrm{Ce}$ & 251,80 & 321,50 & 280,30 & 343,20 & 392,80 & 380,70 & 362,30 & 815,80 \\
$\mathrm{Pr}$ & 28,76 & 39,47 & 33,21 & 41,17 & 48,28 & 50,77 & 42,65 & 117,60 \\
$\mathrm{Nd}$ & 130,40 & 173,90 & 144,60 & 182,20 & 216,50 & 223,60 & 186,60 & 562,30 \\
$\mathrm{Sm}$ & 29,23 & 41,52 & 31,88 & 42,23 & 49,75 & 51,42 & 38,34 & 132,71 \\
$\mathrm{Eu}$ & 8,19 & 11,10 & 9,00 & 11,45 & 13,94 & 14,35 & 11,40 & 34,73 \\
$\mathrm{Gd}$ & 39,41 & 54,16 & 42,00 & 54,73 & 68,01 & 66,67 & 52,34 & 160,49 \\
$\mathrm{~Tb}$ & 6,21 & 8,44 & 6,51 & 8,49 & 10,47 & 10,11 & 8,09 & 23,88 \\
$\mathrm{Dy}$ & 36,45 & 48,74 & 38,56 & 47,71 & 59,81 & 57,08 & 47,56 & 127,77 \\
$\mathrm{Ho}$ & 7,43 & 10,59 & 8,80 & 10,66 & 13,36 & 12,11 & 10,66 & 25,49 \\
$\mathrm{Er}$ & 19,49 & 27,15 & 23,40 & 26,97 & 34,03 & 29,73 & 27,80 & 59,63 \\
$\mathrm{Tm}$ & 2,38 & 3,21 & 2,81 & 3,32 & 4,11 & 3,31 & 3,36 & 6,41 \\
$\mathrm{Yb}$ & 12,32 & 16,64 & 15,05 & 17,82 & 21,43 & 16,93 & 17,01 & 29,75 \\
$\mathrm{Lu}$ & 1,73 & 2,32 & 2,10 & 2,46 & 2,95 & 2,27 & 2,22 & 3,74 \\
\hline$\Sigma_{\text {ETR }}$ & 669,80 & 886,14 & 755,22 & 934,31 & 1094,34 & 1060,25 & 946,63 & 2345,60 \\
$\Sigma_{\text {ETRL }}$ & 544,38 & 714,89 & 615,99 & 762,15 & 880,17 & 862,04 & 777,59 & 1908,44 \\
$\Sigma_{\text {ETRP }}$ & 125,42 & 171,25 & 139,23 & 172,16 & 214,17 & 198,21 & 169,04 & 437,16 \\
\hline $\mathrm{La}_{\mathrm{N}} / \mathrm{Eu}_{\mathrm{N}}$ & 0,47 & 0,46 & 0,52 & 0,50 & 0,46 & 0,40 & 0,48 & 0,28 \\
$\mathrm{Gd}_{\mathrm{N}} / \mathrm{Lu}_{\mathrm{N}}$ & 1,89 & 1,94 & 1,66 & 1,84 & 1,91 & 2,44 & 1,95 & 3,56 \\
$\mathrm{La}_{\mathrm{N}} / \mathrm{Lu}_{\mathrm{N}}$ & 0,81 & 0,81 & 0,82 & 0,85 & 0,79 & 0,91 & 0,90 & 0,96 \\
$\mathrm{Eu} / \mathrm{Eu}^{*}$ & 1,08 & 1,06 & 1,11 & 1,07 & 1,08 & 1,11 & 1,14 & 1,08 \\
$\mathrm{Ce} / \mathrm{Ce}^{*}$ & 1,08 & 1,03 & 1,02 & 1,02 & 1,01 & 1,04 & 1,09 & 1,07 \\
${\mathrm{Ce} / \mathrm{Ce}^{*}}_{\mathrm{f}}$ & 1,29 & 1,24 & 1,22 & 1,22 & 1,21 & 1,24 & 1,30 & 1,28 \\
\hline
\end{tabular}

$\mathrm{Eu} / \mathrm{Eu}^{*}=2 \mathrm{Eu}_{N} /\left(\mathrm{Sm}_{N}+\mathrm{Gd}_{N}\right)-$ razões calculadas utilizando valores das análises normalizados pelo North America Shale Composite (Gromet et al., 1984); $\mathrm{Ce} / \mathrm{Ce}^{*}=3 \mathrm{Ce}_{\mathrm{N}} /\left(2 \mathrm{La}_{\mathrm{N}}+\mathrm{Nd}_{N}\right)$ - razões calculadas utilizando valores das análises normalizados pelo North America Shale Composite (Gromet et al., 1984); Ce/Ce ${ }_{\mathrm{f}}=$ $3 \mathrm{Ce}_{\mathrm{NN}} /\left(2 \mathrm{La}_{\mathrm{Nt}}+\mathrm{Nd}_{\mathrm{Ni}}\right)-$ razốes calculadas utilizando valores das análises normalizados pela média das fosforitas marinhas de Magdalena Bay (Goldberg et al., 1963). 
máxima. Ambas as fontes parecem ter atuado na formação das rochas fosfáticas de Rio Verde de Mato Grosso, como comprovado pela presença de pontuações de oxi-hidróxidos em abundância nessas camadas. A textura lutítica, a estrutura nodular ou envelopada e o modo de ocorrência restrito indicam que essa camada representa um evento distinto da sedimentação da unidade, como uma superfície de inundação máxima na interface água-sedimento.

Considerando preferencialmente a formação autigênica de fosfatos pela dessorção a partir de oxi-hidróxidos, Föllmi (1996) comenta que a susceptibilidade à redução dos oxi-hidróxidos de ferro é menor que a susceptibilidade dos oxi-hidróxidos de manganês, o que acabaria resultando na preservação de relictos de oxi-hidróxidos de ferro com fosfato adsorvido em sedimentos anóxicos. Essa informação é plenamente coerente com o observado na camada fosfática estudada, em que há preservação frequente de oxi-hidróxidos de ferro pulverulentos, mas pouca ou nenhuma evidência da preservação de oxi-hidróxidos de manganês.
Föllmi (1996) também cita o mecanismo de "iron pump and shuttle" (bombeamento e transporte de ferro, em tradução livre) proposto por Shaffer (1986), que em bacias oceânicas óxicas-anóxicas - a exemplo do Mar Negro — gera concentrações muito mais baixas e muito mais altas de fosfatos, respectivamente acima e abaixo do limite redox, do que o previsto por modelos estequiométricos. Esse mecanismo seria mais atuante em ambientes não associados a zonas de ressurgência, onde há grande aporte de oxi-hidróxidos de ferro e manganês provenientes de massas de água continentais, com altas taxas de sedimentação e frequente bioturbação. Nos folhelhos hospedeiros da camada fosfática podem ser observados estratos bioturbados, além da presença de oxi-hidróxidos, o que indica, então, que esses fosfatos não são associados a zonas de ressurgência.

O mecanismo de "iron pump and shuttle" também seria atuante de forma significativa próximo a regiões com atividade hidrotermal e vulcânica submarina, onde haveria formação constante de oxi-hidróxidos de ferro e manganês, o
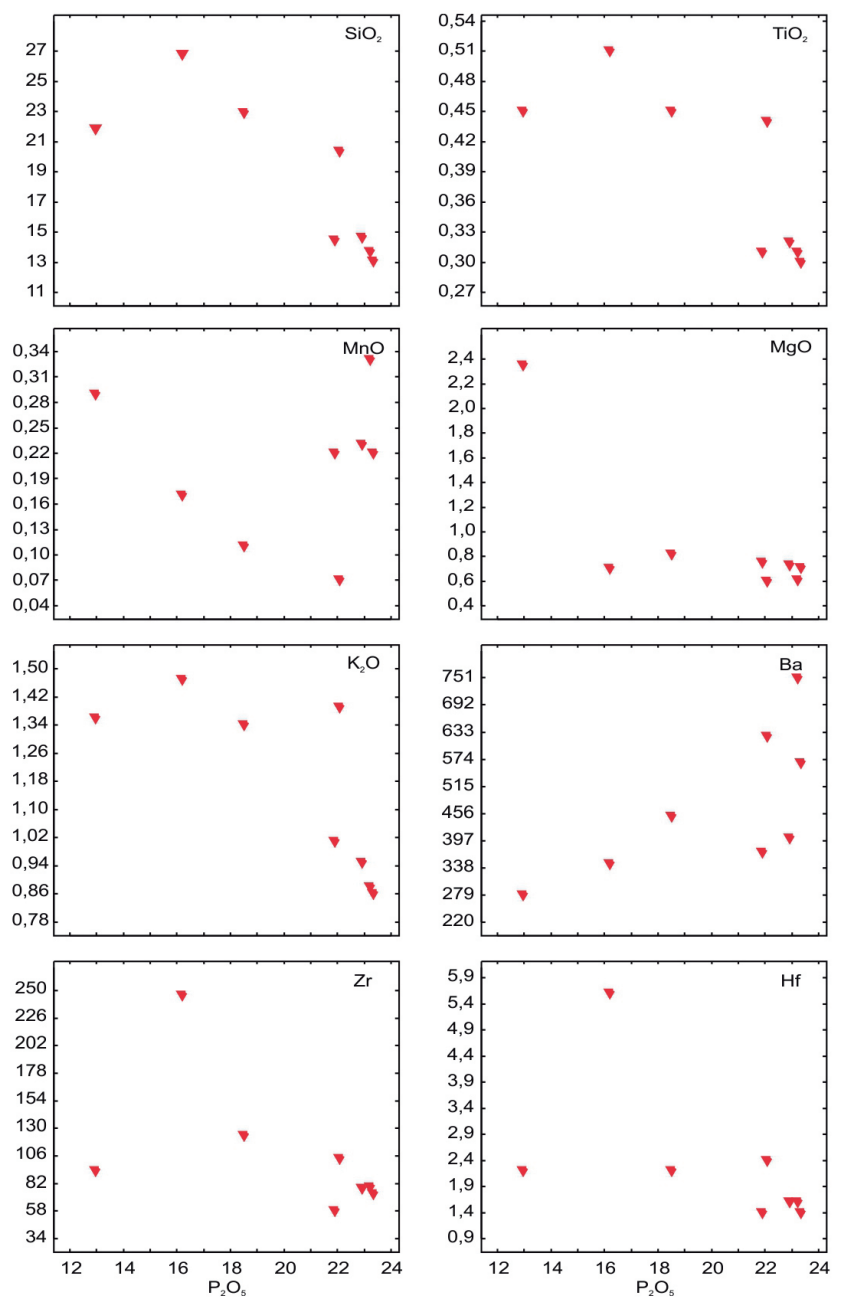
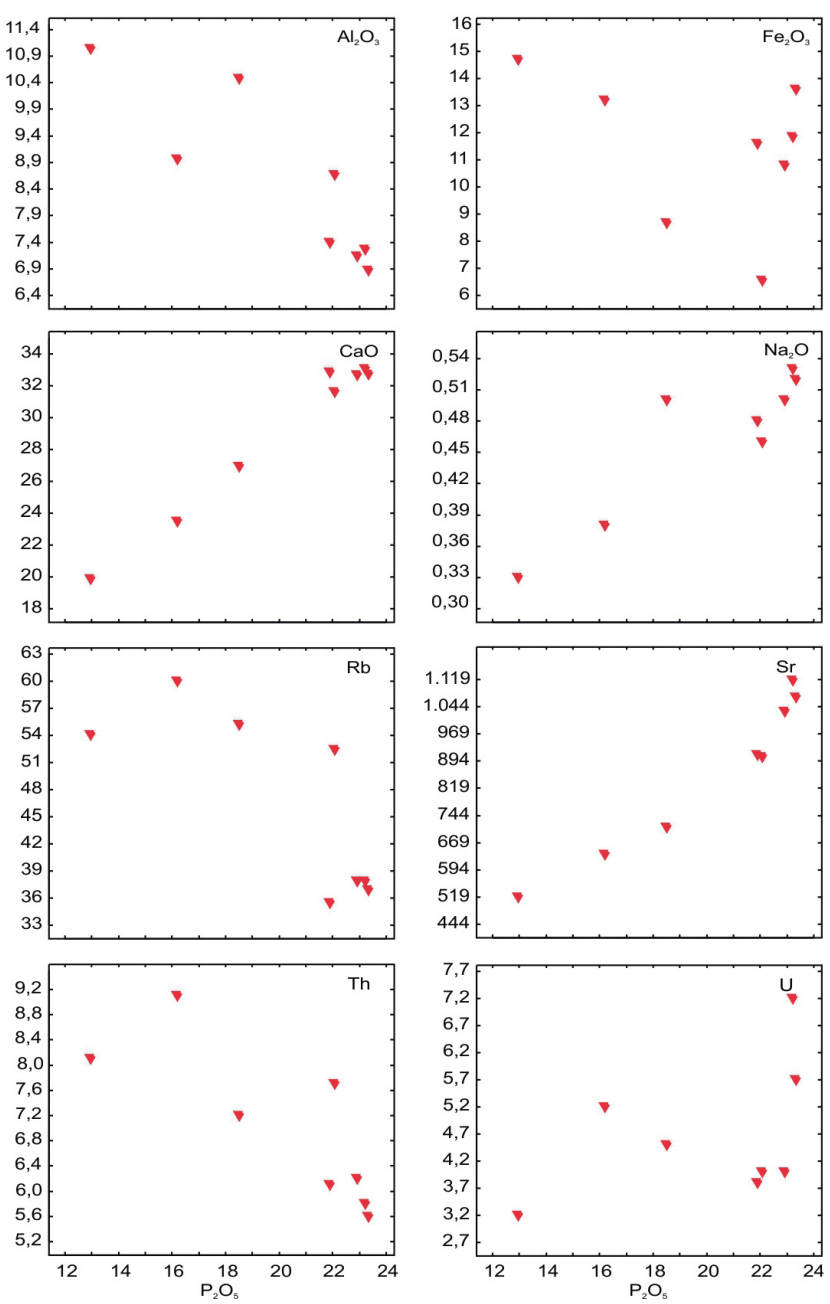

Figura 8. Diagramas binários do tipo $\mathrm{M}$ versus $\mathrm{P}_{2} \mathrm{O}_{5}$ para as amostras de camada fosfática de Rio Verde de Mato Grosso, Mato Grosso do Sul, onde M representa elementos maiores e alguns traços selecionados. 
que não representa o contexto da Formação Ponta Grossa, excluindo-se, portanto, essa possibilidade.

McArthur e Walsh (1984) discutem a fonte dos ETR em $\mathrm{NFs}$, sendo que o carbonato-fluorapatita (francolita) se forma em ambientes com baixa disponibilidade de ETR. Os modos de concentração de fosfatos, relacionados à precipitação não biogênica, tendem a acumular maiores concentrações de ETR, provenientes predominantemente da água intraporos dos próprios nódulos ou camadas, da água de formação em migração e de águas subterrâneas, parcialmente pela água do mar nos quais estes foram depositados e secundariamente herdados do mineral pretérito em caso de fosfatização de carbonatos (McArthur e Walsh, 1984). Os ETR são enriquecidos na água intraporos pela reação diagenética durante o soterramento e a compactação desses sedimentos, por meio da migração de fluidos e concentração em porções oclusas ou em fechamento, e são, então, incorporados na francolita durante a diagênese tardia e a catagênese.

A partir dessas afirmações, McArthur e Walsh (1984) observaram e concluíram que:

1. francolitas onshore têm maior abundância de ETR do que as francolitas offshore em decorrência da maior
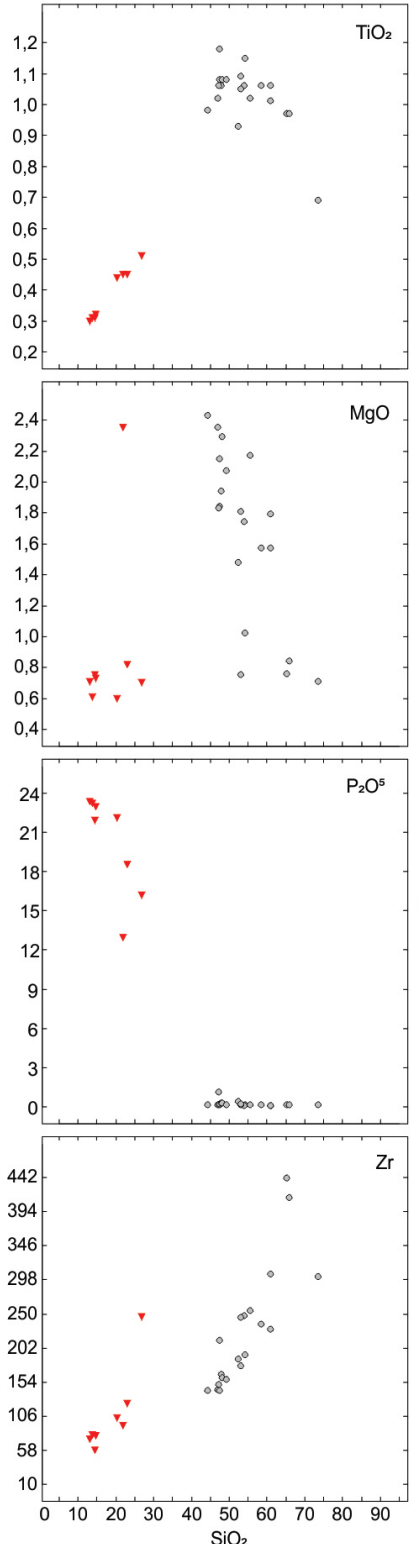
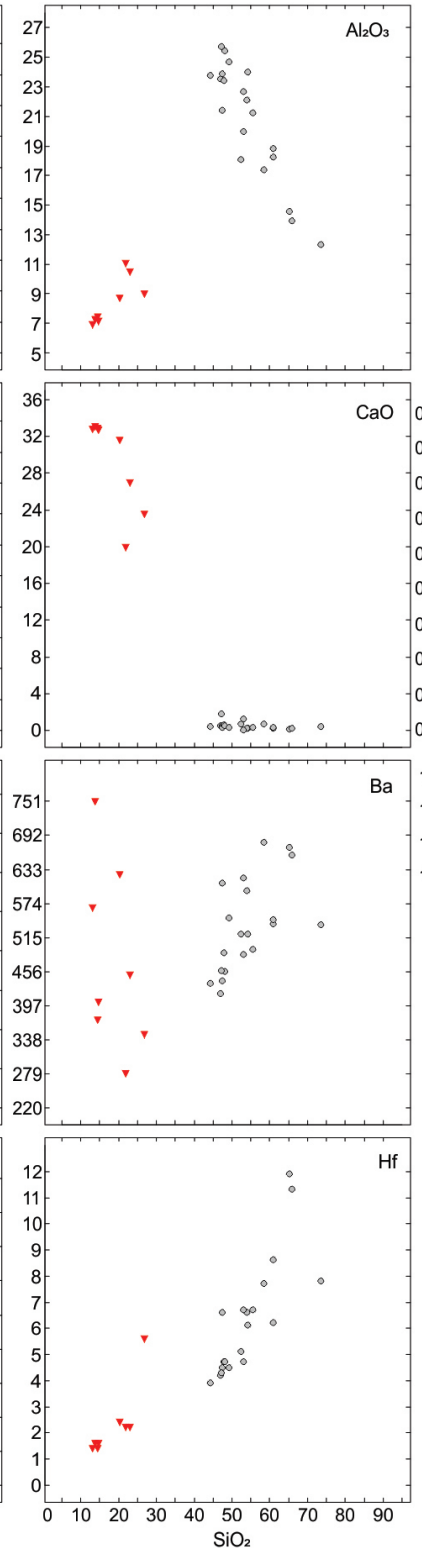
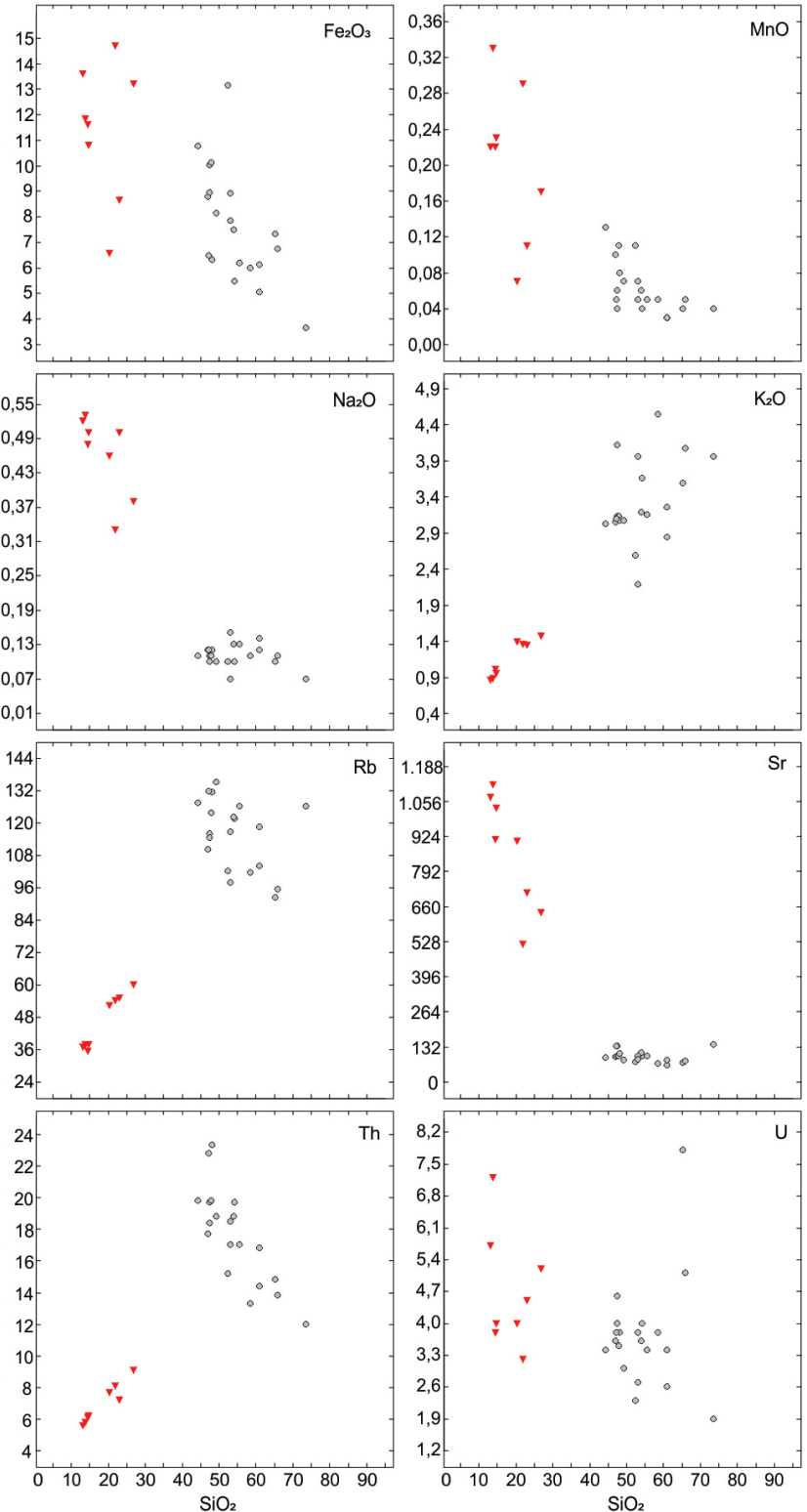

Triângulos vermelhos: camada fosfática; círculos cinzas: folhelhos cinzas-escuros a pretos.

Figura 9. Diagramas binários do tipo $\mathrm{M}$ versus $\mathrm{SiO}_{2}$ para amostras de Rio Verde de Mato Grosso, Mato Grosso do Sul, onde $\mathrm{M}$ representa elementos maiores e alguns traços selecionados. 
susceptibilidade das amostras onshore à ação da migração de fluidos como resultados do intemperismo e da movimentação das águas subterrâneas;

2. amostras de NFs não biogênicas "peletais" têm maior abundância de ETR do que a maioria das amostras "não peletais", por conta da área superficial maior das amostras peletais, permitindo maior incorporação a partir de fluidos intraporos;

3. NFs mais velhas são mais enriquecidas em ETR do que NFs mais recentes por conta do tempo de residência dos sedimentos, dando a eles mais tempo para gerar reações de incorporação de ETR a partir da água intraporos - em geral, a abundância de ETR aumenta com o aumento da idade da amostra, e amostras do Pleistoceno ao recente possuem abundâncias de ETR muito baixas.

As NFs de Rio Verde de Mato Grosso têm maior conteúdo em ETR do que as NFs offshore de Magdalena Bay, por um lado por serem mais antigas e com maior tempo de residência e, por outro, por serem microcristalinas, logo, com alta porosidade, permitindo maior incorporação de água intraporos.

Como comparativo, Emsbo et al. (2015) apresentam as concentrações relativas de ETR e seus padrões de distribuições para NFs de diferentes idades e diversas regiões, predominantemente dos Estados Unidos, e sugerem que esses padrões são específicos no tempo e têm potencial para correlações cronoestratigráficas. Em comparação com os diagramas de Emsbo et al. (2015), as NFs de Rio Verde de Mato Grosso possuem padrão de distribuição de ETR similar ao de fosfatos do Devoniano, com enriquecimento em ETR intermediário, como era de se esperar, mas apresentam menores concentrações, o que pode ser explicado, além da diferença no contexto tectono-sedimentar, pela condição offshore das NFs de Rio Verde de Mato Grosso, ou pelo efeito de diluição provocado pela presença de silicatos detríticos englobados pelos fosfatos na rocha estudada.

Baturin (1982) também destaca que as NFs modernas estão localizadas predominantemente ao longo da costa oeste da América do Sul e ao longo da costa oeste do continente africano, e coloca a combinação de fatores meteorológicos, oceanográficos, biológicos e geológicos dessas regiões como determinantes para a formação de acumulações fosfáticas. Essas condições seriam:

1. a direção e a intensidade dos ventos (aproximadamente sudeste e sul, com velocidade média de $5-10 \mathrm{~m} / \mathrm{s}$ );

2. a movimentação de correntes marinhas e massas aquáticas (águas predominantemente frias, com cerca de 11 $17^{\circ} \mathrm{C}$, e de baixa salinidade, em torno de $34-35 \%$, provenientes da Antártica);

3. o estabelecimento de zonas de ressurgência.

Outros fatores, como o clima, a composição química das águas e a concentração de organismos vivos, são decorrentes da ação dos três fatores supracitados. Entretanto, Föllmi (1996) cita a crescente importância de trabalhos que descrevem a formação de fosfatos autigênicos dispersos localizados em ambientes marinhos não associados a zonas de ressurgência, como regiões costeiras e ambientes deltaicos. Não é possível considerar ambiente deltaico na região de Rio Verde de Mato Grosso, mas a presença de arenitos poucos metros acima da camada fosfática indica condição ainda nos limites da plataforma.

Segundo Baturin (1982), na região da corrente de Benguela, a profundidade da qual as águas ascendem em um evento de ressurgência não é maior que $200-300 \mathrm{~m}$, como demonstrado pelos dados de temperatura e salinidade, sendo que a camada superior de água ressurgente (primeiros $50 \mathrm{~m}$ de profundidade) possui as mesmas características da camada de água encontrada no intervalo de $200-250 \mathrm{~m}$ de

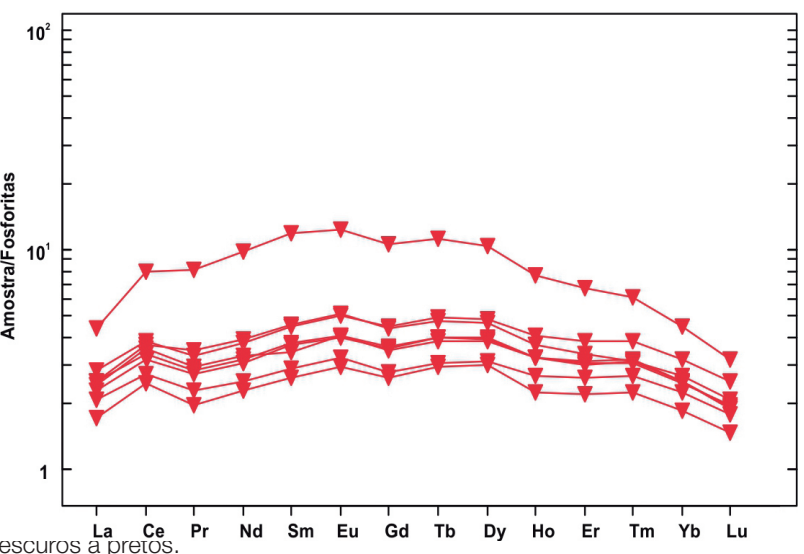

Círculos vermelhos: camada fosfática; círculos cinzas: folhelhos encaixantes cinzas-escurus da preıus. ${ }^{\mathrm{Pr}} \mathrm{Nd}$. Grosso do Sul, normalizados pelo North America Shale Composite (Gromet et al., 1984); (B) diagramas multielementares de elementos terras raras para as amostras normalizadas pelo valor médio de fosforitas marinhas (Goldberg et al., 1963). 
profundidade do talude continental. Se fossem geradas por zonas de ressurgência - o que não parece ser o caso as NFs estudadas indicariam, então, condições de ambiente marinho plataformal raso, com profundidade entre $200 \mathrm{e}$ $300 \mathrm{~m}$, de águas frias e com baixa salinidade, preferencialmente anóxico.

Considerando as condições discutidas anteriormente, a camada fosfática descrita em Rio Verde de Mato Grosso apresenta grandes concentrações de $\mathrm{P}_{2} \mathrm{O}_{5}$, e está alojada em sedimentos que passaram por evento anóxico/redutor, como é comprovado pela presença frequente de nódulos de pirita nos folhelhos hospedeiros. Isso sugere que sua origem é autigênica e relacionada à liberação de fósforo a partir da redução de sulfatos ou óxidos. Como pode ser observado ao microscópio petrográfico, essas ocorrências não possuem evidências de ação biogênica, o que é confirmado pela microscopia eletrônica. Também são encontrados abundantes relictos de oxi-hidróxidos, preferencialmente de ferro, com pequena quantidade de manganês, o que reforça a origem pela dessorção de fosfato por comportamento redox a partir desses relictos. Uma hipótese a ser considerada, caso seja possível associar as pontuações de oxi-hidróxidos a produtos de alteração de pirita, é que estas sejam correspondentes a framboides originados por bactérias redutoras de sulfato, $\mathrm{o}$ que, na verdade, carece de confirmação, por essas bactérias terem sido descritas preferencialmente em zonas de ressurgência (Schulz e Schulz, 2005). Assim, as concentrações de fosfato provavelmente se formaram na interface água-sedimento e, estratigraficamente, devem representar uma superfície de inundação máxima próxima do limite redox da bacia sedimentar na qual se formou. Os conteúdos em ETR são mais altos do que aqueles geralmente descritos em NFs, e apresentam padrões de distribuição similares a carbonato-fluorapatitas do Devoniano dos Estados Unidos (Emsbo et al., 2015), embora com conteúdo menor, provavelmente por conta do efeito de diluição provocado pela presença de minerais detríticos silicáticos englobados pelos fosfatos.

\section{CONCLUSÕES}

Os aspectos mineralógicos, estruturais e texturais sugerem que a deposição ocorreu em ambiente de baixa energia, por meio de precipitação gravitacional de partículas finas, com predomínio de delgadas palhetas de filossilicatos sobre os outros minerais detríticos, a exemplo do quartzo.

Pelos comentários existentes na literatura em confronto com a descrição desta camada fosfática e seu contexto, a explicação mais coerente para a sua formação é a de uma redução significativa na deposição de detritos, enquanto ocorre a compactação lenta dos estratos ricos em matéria orgânica subjacente. A presença de siderita e de nódulos de pirita nos folhelhos cinzas a pretos que hospedam essa camada indica que durante certo período se estabeleceu um ambiente altamente redutor. A compactação levou à liberação de fósforo e ETR, que migraram para a interface água-sedimento, na qual o ambiente era menos redutor, possibilitando a precipitação química do material fosfático, com abundante água intraporos, o que permitiu a incorporação de ETR nas francolitas. Essa camada indica que não houve estabelecimento de zona de ressurgência, e sim mecanismos químicos e bioquímicos pela atuação de bactérias redutoras do sulfato e metabolizantes do fósforo gerado pela decomposição da matéria orgânica, que permitiram posterior acumulação química de fosfatos ainda durante o processo de sedimentação siliciclástica da bacia, em um evento de redução do aporte detrítico, representando uma superfície de inundação máxima.

\section{AGRADECIMENTOS}

Ao Conselho Nacional de Desenvolvimento Científico e Tecnológico (CNPq) (processo $\mathrm{n}^{\circ} 304535 / 2011-7$ e processo $\left.n^{\circ} 165168 / 2013-7\right)$.

\section{REFERÊNCIAS}

Assine, M. L., Soares, P. C., Milani, E. J. (1994). Sequências tectono-sedimentares mesopaleozóicas da Bacia do Paraná, Sul do Brasil. Revista Brasileira de Geociencias, 24(2), 77-89.

Baturin, G. N. (1982). Phosphorites on the Sea Floor. In: P. J. Ashworth, J. L. Best, D. R. Parsons (Eds.). Developments in Sedimentology (33). Amsterdam: Elsevier. 343 p.

Bentor, Y. K. (Ed.) (1980). Marine Phosphorites Geochemistry, Occureence, Genesis. In: X International Congress on Sedimentology in Jerusalem, Israel, 9-14 July 1978. Special Publication, n. 29. November, 1980. Tulsa, Oklahoma, USA: Society of Economic Paleontologists and Mineralogists.

Boggiani, P. C., Coimbra, A. M., Riccomini, C., Gesicki, A. L. D. (1998). Recursos Minerais Não-metálicos do Estado de Mato Grosso do Sul. Revista IG São Paulo, 19(1/2), 31-41.

Caputo, M. V.(1985). Late Devonian glaciation in South America. Palaeogeography, Palaeoclimatology, Palaeoecology, 51, 291-317. https://doi.org/10.1016/0031-0182(85)90090-2

Copper, P. (1977). Paleolatitudes in the Devonian of Brazil and the Frasnian-Famennian mass extinction. Palaeogeography, Palaeoclimatology, Palaeoecology, 21, 165-207. https://doi. org/10.1016/0031-0182(77)90020-7 
Copper, P. (2002). Reef development at the Frasnian/ Famennian mass extinction boundary. Palaeogeography, Palaeoclimatology, Palaeoecology, 181, 27-65. https://doi. org/10.1016/S0031-0182(01)00472-2

Dypvik, H., Zakharov, V. (2010). Late Jurassic/Early Cretaceous phosphates of Nordvik, North Siberian Basin. Polar Research, 29, 235-249. https://doi.org/10.3402/polar.v29i3.6079

Emsbo, P., McLaughlin, P. I., Breit, G. N., Bray, E. A., Du Koenig, A. E. (2015). Rare earth elements in sedimentary phosphate deposits: Solution to the global REE crisis? Gondwana Research, 27, 776-785. https://doi.org/10.1016/j. gr.2014.10.008

Fazio, A. M., Scasso, R. A., Castro, L. N., Carey, S. (2007). Geochemistry of rare earth elements in early-diagenetic miocene phosphatic concretions of Patagonia, Argentina: Phosphogenetic implications. Deep-Sea Research II, 54, 1414-1432. https://doi.org/10.1016/j.dsr2.2007.04.013

Filippelli, G. M. (2011). Phosphate rock formation and marine phosphorus geochemistry: The deep time perspective. Chemosphere, 84, 759-766. https://doi.org/10.1016/j. chemosphere.2011.02.019

Föllmi, K. B. (1996). The phosphorus cycle, phosphogenesis and marine phosphate-rich deposits. Earth-Science Reviews, 40, 55-124. https://doi.org/10.1016/0012-8252(95)00049-6

Grahn, Y., Mendlowicz Mauller, P., Pereira, E., Loboziak, S. (2010). Palynostratigraphy of the Chapada Group and its significance in the Devonian stratigraphy of the Paraná Basin, south Brazil. Journal of South American Earth Sciences, 29, 354-370. https://doi.org/10.1016/j.jsames.2009.09.001

Garnit, H., Bouhlel, S., Barca, D., Chtara, C. (2012). Application of LA-ICP-MS to sedimentary phosphatic particles from Tunisian phosphorite deposits: Insights from trace elements and REE into paleo-depositional environments. Chemie der Erde, 72, 127-139. DOI: 10.1016/j. chemer.2012.02.001

Goldberg, E. D., Koide, M., Schmitt, R. A., Smith, R. H. (1963). Rare-Earth Distributions in the Marine Environment. Journal of Geophysical Research, 68(14), 4209-4217. DOI: 10.1029/JZ068i014p04209

Gromet, L. P., Haskin, L. A., Korotev, R. L., Dymek, R. F. (1984). The "North American Shale Composite": its compilation, major and trace element characteristics. Geochimica et Cosmochimica Acta, 48, 2469-2482. https:// doi.org/10.1016/0016-7037(84)90298-9
Hüneke, H. (2006). Erosion and deposition from bottom currents during the Givetian and Frasnian: Response to intensified oceanic circulation between Gondwana and Laurussia. Palaeogeography, Palaeoclimatology, Palaeoecology, 234, 146-167. https://doi.org/10.1016/j. palaeo.2005.09.033

Ilyin, A. V. (1998). Rare-earth geochemistry of 'old' phosphorites and probability of syngenetic precipitation and accumulation of phosphate. Chemical Geology, 144, 243-256. DOI: 10.1016/S0009-2541(97)00134-4

Joachimski, M. M., Breisig, S., Buggisch, W., Talent, J. A., Mawson, R., Gereke, M., Morrow, J. R., Day, J., Weddige, K. (2009). Devonian climate and reef evolution: Insights from oxygen isotopes in apatite. Earth and Planetary Science Letters, 284, 599-609. https://doi.org/10.1016/j. eps1.2009.05.028

Lacerda Filho, J. W., Silva, M. G., Jost, H. (2006). Geologia e Recursos Minerais do Estado de Mato Grosso do Sul. Programa Integração. Atualização e Difusão de Dados de Geologia do Brasil. Brasil: Convênio CPRM/ SICMEMS, MME. $121 \mathrm{p}$.

Lange, F. W., Petri, S. (1967). The Devonian of the Paraná Basin. Boletim Paranaense de Geociências, (21-22), 5-55.

McArthur, J. M. E., Walsh, J. N. (1984). Rare-earth geochemistry of phosphorites. Chemical Geology, 47, 191-220. https://doi.org/10.1016/0009-2541(84)90126-8

Milani, E. J. (1997). Evolução tectono-estratigráfica da Bacia do Paraná e seu relacionamento com a geodinâmica fanerozóica do Gondwana sul-ocidental. Tese (Doutorado). Porto Alegre: Universidade Federal do Rio Grande do Sul - UFRGS.

Montibeller, C. C. (2015). Características químicomineralógicas e cerâmicas da matéria-prima utilizada pelo polo cerâmico de Rio Verde de Mato Grosso, MG. Dissertação (Mestrado). Rio Claro: Instituto de Geociências e Ciências Exatas - UNESP.

Montibeller, C. C., Zanardo, A. (2014a). Nível fosfático da Formação Ponta Grossa em Rio Verde de Mato Grosso, MS. In: XLVII Congresso Brasileiro de Geologia. Salvador: SBG.

Montibeller, C. C., Zanardo, A. (2014b). Petrografia de alguns estratos da Formação Ponta Grossa de Rio Verde de Mato Grosso, MS. In: XLVII Congresso Brasileiro de Geologia. Salvador: SBG. 
Montibeller, C. C., Zanardo, A., Navarro, G. R. B. (2017). Decifrando a proveniência dos folhelhos da formação Ponta Grossa na região de Rio Verde de Mato Grosso e Coxim (MS) através de métodos petrográficos e geoquímicos. Geologia USP. Série Científica, 17(1), 41-59. http://dx.doi.org/10.11606/issn.2316-9095. v17-294

Oliveira, E. P. (1912). O Terreno Devoniano ao Sul do Brasil. Anais da Escola de Minas de Ouro Preto, 14, 31-41.

Petrelli, M., Poli, G., Perugini, D., Peccerillo, A. (2005). Petrograph: a new software to visualize, model, and present geochemical data in igneous petrology. Geochemistry, Geophysics, Geosystems, 6(7), 1-15. DOI: 10.1029/2005GC000932
Rudnick, R. L., Gao, S. (2003). Composition of the Continental Crust. Composition of the continental crust. In: R. L. Rudnick (Ed.). The Crust (1-70). Amsterdam: Elsevier.

Schulz, H. N., Schulz, H. D. (2005). Large Sulfur Bacteria and the Formation of Phosphorite. Science, 307(5708), 416-418. DOI: 10.1126/science. 1103096

Shaffer, G. (1986). Phosphate pumps and shuttles in the Black Sea. Nature, 321, 515-517. DOI: 10.1038/321515a0

Sholkovitz, E. (1973). Interstitial water chemistry of the Santa Barbara Basin sediments. Geochimica et Cosmochimica Acta, 37, 2043-2073. https://doi.org/10.1016/0016-7037(73)90008-2

Slansky, M. (1986). Geology of Sedimentary Phosphates. Triptree, Essex: Anchor Brendon. 210 p. 